\title{
How Much Carbon Pricing is in Countries' Own Interests? The Critical Role of Co-Benefits
}




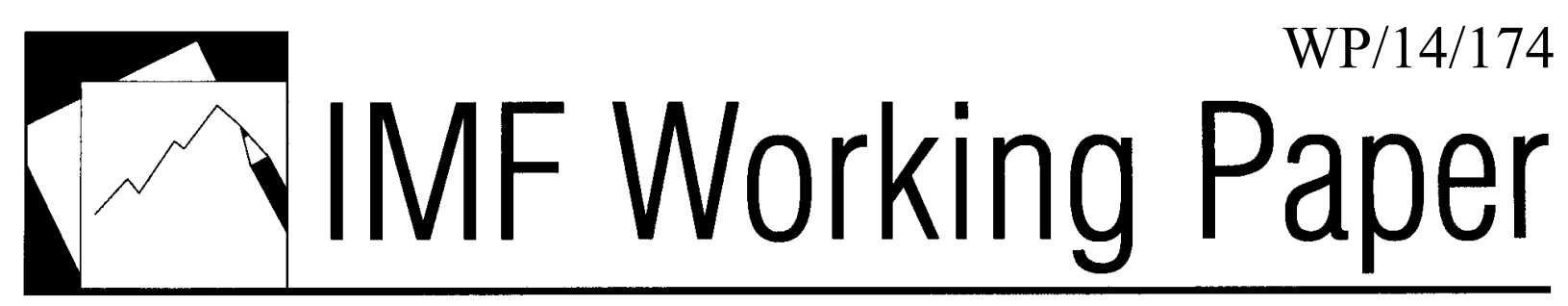

\title{
How Much Carbon Pricing is in Countries' Own Interests? The Critical Role of Co-Benefits
}

\author{
Ian Parry, Chandara Veung, and Dirk Heine*
}

*Parry and Veung: Fiscal Affairs Department, IMF; Heine: University of Bologna. We are grateful to Jorge Alvarez, Tim Callen, Alfredo Cuevas, Vitor Gaspar, Michael Keen, Francisco Roch, Carlo Sdralevich, and Roman Zytek for very helpful comments and suggestions on an earlier draft. 


\title{
IMF Working Paper
}

Fiscal Affairs Department

\section{How Much Carbon Pricing is in Countries' Own Interests? The Critical Role of Co-Benefits}

\author{
Prepared by Ian Parry, Chandara Veung, and Dirk Heine
}

Authorized for distribution by Michael Keen

September 2014

\section{This Working Paper should not be reported as representing the views of the IMF.} The views expressed in this Working Paper are those of the author(s) and do not necessarily represent those of the IMF or IMF policy. Working Papers describe research in progress by the author(s) and are published to elicit comments and to further debate.

\begin{abstract}
This paper calculates, for the top twenty emitting countries, how much pricing of carbon dioxide $\left(\mathrm{CO}_{2}\right)$ emissions is in their own national interests due to domestic co-benefits (leaving aside the global climate benefits). On average, nationally efficient prices are substantial, $\$ 57.5$ per ton of $\mathrm{CO}_{2}$ (for year 2010), reflecting primarily health co-benefits from reduced air pollution at coal plants and, in some cases, reductions in automobile externalities (net of fuel taxes/subsidies). Pricing co-benefits reduces $\mathrm{CO}_{2}$ emissions from the top twenty emitters by 13.5 percent (a 10.8 percent reduction in global emissions). However, co-benefits vary dramatically across countries (e.g., with population exposure to pollution) and differentiated pricing of $\mathrm{CO}_{2}$ emissions therefore yields higher net benefits (by 23 percent) than uniform pricing. Importantly, the efficiency case for pricing carbon's co-benefits hinges critically on (i) weak prospects for internalizing other externalities through other pricing instruments and (ii) productive use of carbon pricing revenues.
\end{abstract}

JEL Classification Numbers: H23, Q48, Q54, Q58

Keywords: carbon pricing; co-benefits; air pollution; fuel taxes; top twenty emitters Author's E-Mail Address: Iparry@imf.org; daraveung@gmail.com; dheine@posteo.de 
Abstract. .$\underline{2}$

I. Introduction $\underline{4}$

II. Defining and Measuring Nationally Efficient $\mathrm{CO}_{2}$ Prices .......................................... $\underline{6}$

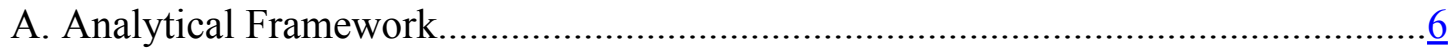

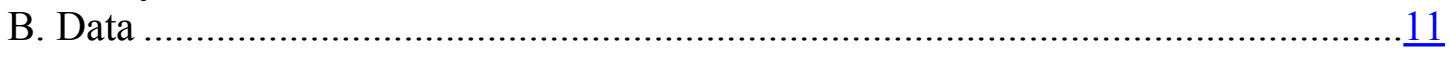

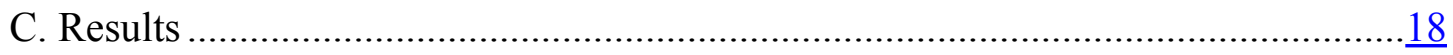

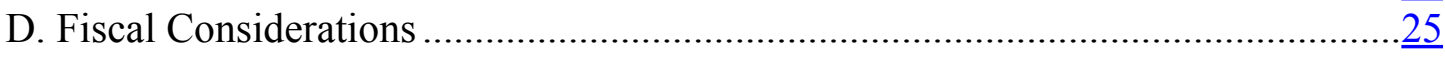

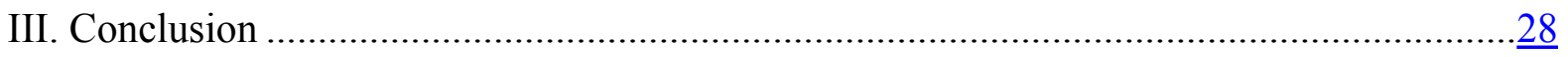

Figures

1. Net Benefits from a Pre-Existing Fuel Tax................................................................

2. Net Benefits from a CO2 Charge on an Individual Fuel .............................................. $\frac{10}{12}$

3. CO2 Emission Shares and Intensity, 2010 ........................................................... $\frac{12}{13}$

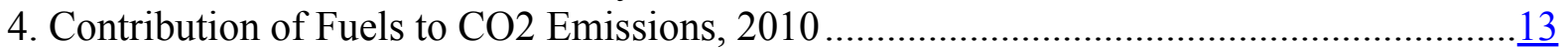

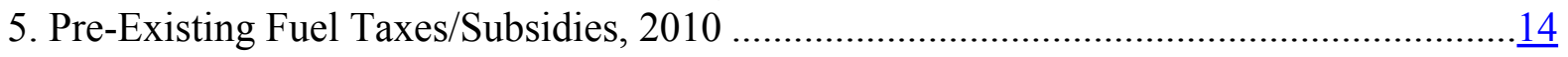

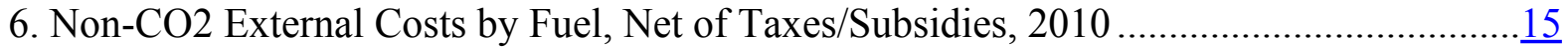

7. Nationally Efficient CO2 Prices due to Domestic Co-Benefits, 2010 .............................19

8. Emissions Reductions, and Sources of Reductions by Fuel Type, 2010 .......................... $\underline{20}$

9. Breakdown of Nationally Efficient Carbon Price by Fuel Type, 2010.............................21

10. Net Benefits from Nationally Efficient and Uniform Pricing, 2010 .............................23

11. Revenue from Nationally Efficient Carbon Prices, 2010 ..........................................26

12. Net Benefits from Carbon Pricing Accounting for Fiscal Linkages, 2010 ......................29

Box

1. Other Externalities from Energy Use....................................................................

Appendix

Methodology Underlying non-CO2 External Damages .............................................. 30

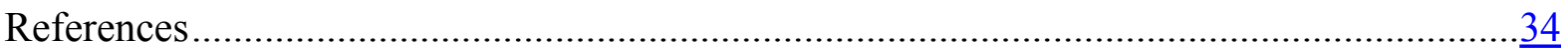




\section{INTRODUCTION}

There has been much agonizing over achieving the collective benefits from addressing global climate change. However, pricing carbon dioxide $\left(\mathrm{CO}_{2}\right)$ emissions from fossil fuel use can produce important national co-benefits. Most obviously, as carbon charges reduce use of coal, natural gas, and petroleum products, this reduces the amount of people killed by outdoor air pollution, currently estimated at 3.7 million a year worldwide. ${ }^{1}$ To take another example, if congestion, accidents, and other externalities from motor vehicle use are not fully internalized through other pricing policies, again there are potentially significant cobenefits to the extent that carbon charges reduce vehicle use. The potential for co-benefits suggests that countries need not wait on internationally coordinated efforts if some carbon mitigation is in their own national interests - that is, the domestic environmental benefits exceed the $\mathrm{CO}_{2}$ mitigation costs, leaving aside climate benefits.

These considerations raise three important questions for policy.

First, what scale of $\mathrm{CO}_{2}$ pricing is in countries' own interests and how this would affect $\mathrm{CO}_{2}$ emissions? Ideally non- $\mathrm{CO}_{2}$ externalities would be internalized through other policies, including charges for air emissions from coal and for peak-period driving on congested roads. However, until such policies are comprehensively implemented (likely a long time given that no country presently has anything like fully corrective charges) it is entirely appropriate to price $\mathrm{CO}_{2}$ emissions for domestic co-benefits (prior to assessing additional measures warranted by global concerns).

Second, given cross-country heterogeneity in co-benefits (and medium-run constraints on internalization of co-benefits through other policy instruments), efficiency requires differentiated carbon prices across countries, with prices higher in countries with greater co-benefits per ton of $\mathrm{CO}_{2}$ reductions. The question is whether the extra benefits from nationally efficient carbon pricing, compared with uniform pricing (resulting, for example, from linking trading systems), are empirically large-if so, this suggests the potential superiority of pricing regimes allowing countries to choose their own emission prices (ideally subject to some agreed minimum price reflecting global climate damages) over agreements inducing all countries to price emissions at the same rate.

The third question is how much revenue is raised from nationally efficient $\mathrm{CO}_{2}$ pricing and how revenue use might affect the net benefits from pricing co-benefits in different countries. In the latter regard, prior literature (e.g., Goulder et al. 1999, Parry et al. 1999) emphasizes the large differences in costs between carbon pricing policies where revenues are used productively_most obviously to lower the burden of income and other taxes that distort the level of economic activity and its composition-versus carbon pricing policies (like trading systems with free allowance allocations or carbon taxes with low-value earmarks) that fail to exploit efficiency gains from recycling opportunities.

\footnotetext{
${ }^{1}$ See WHO (2014), though not all of these deaths are due to fossil fuel emissions, and some are jointly determined with indoor air pollution.
} 
This paper seeks to address the above three questions ${ }^{2}$, though the main focus is on assessing nationally efficient $\mathrm{CO}_{2}$ prices, that is, prices reflecting domestic (non-internalized) environmental benefits per ton of $\mathrm{CO}_{2}$ reductions. These prices are based on country-level estimates of (non- $\mathrm{CO}_{2}$ ) environmental damages by fossil fuel product from Parry et al. (2014), and a simple spreadsheet model populated with fuel use, price, and tax/subsidy data, along with simple rules of thumb for the responsiveness of fuel use to carbon pricing. Results are provided for the top twenty $\mathrm{CO}_{2}$ emitting countries, collectively accounting for 80 percent of current, energy-related, global $\mathrm{CO}_{2}$ emissions.

The main findings can be summarized as follows.

As regards the first question, the nationally efficient $\mathrm{CO}_{2}$ price is typically quite large, for example, \$63 per ton-estimated for year 2010 and in US \$ for that year-in China, and averages $\$ 57.5$ per ton among the top twenty emitters. For comparison, a US government study (US IAWG 2013) puts the global damage from $\mathrm{CO}_{2}$ emissions at $\$ 35$ per ton, and $\mathrm{CO}_{2}$ prices in the European Union's Emissions Trading System have been below $\$ 10$ per ton since January 2013. In most cases, co-benefits primarily reflect reduced air pollution deaths from less coal use, though in some cases they primarily reflect reduced road fuel subsidy distortions and reduced vehicle externalities. In a few cases (where health damages from coal are limited and motor fuel excises are broadly in line with, or exceed, non-carbon externalities) nationally efficient $\mathrm{CO}_{2}$ prices are around $\$ 10$ per ton or less, and negative in one case (Brazil, where fuel taxes currently overcharge for domestic externalities). Imposing nationally efficient $\mathrm{CO}_{2}$ prices reduces total $\mathrm{CO}_{2}$ emissions for the top-twenty emitters by 13.5 percent below baseline levels (a reduction in global emissions of 10.8 percent). ${ }^{3}$

On the second policy question, net economic benefits are increased by 23 percent under nationally efficient $\mathrm{CO}_{2}$ prices rather than a uniform price (for the same 13.5 percent reduction in emissions from the largest twenty emitters). This is a significant (though not dramatic) gain and reinforces the pragmatic case for flexible pricing regimes when cobenefits, or more generally fiscal needs and political feasibility differ across countries, or when equity concerns (given constraints on international transfers) warrant lower prices for lower income countries.

As regards the third policy question, on average revenues are large, almost 2 percent of GDP across the top twenty countries. Moreover, if revenues from nationally efficient carbon prices are used to cut broader income taxes, the overall benefits from carbon pricing can increase substantially, on average by about 100 percent (this is the 'double dividend'

\footnotetext{
${ }^{2}$ A further issue, not examined here, is that international emissions offset programs become less attractive from a national perspective to the extent they reduce domestic $\mathrm{CO}_{2}$ abatement and hence domestic co-benefits (e.g., Nemet et al. 2010).

${ }^{3}$ Some other studies discussed below also provide estimates of health co-benefits from reducing $\mathrm{CO}_{2}$, though not for all the twenty countries considered here and leaving aside prior fuel taxes/subsidies and broader externalities.
} 
which can occur when the full range of distortions from the broader fiscal system is properly considered). But if revenue recycling benefits are forgone, the costs of carbon pricing are substantially higher, and actually exceed co-benefits. This underscores the key reservation about environmental taxes, namely the risk that revenues are used for low-value purposescombining carbon taxes with offsetting reductions in other taxes avoids this risk.

The usual caveats about parameter uncertainty apply-due to data constraints and uncertainties (e.g., over pollution/health relationships or the valuation of health effects) cobenefits may be measured with considerable imprecision, though sensitivity analyses suggest the general flavor of the results is robust (if anything, co-benefits may be significantly understated here due to conservative assumptions). Terms of trade effects, which can lower national (but not global) welfare for fuel exporters, are however excluded, as are emissions leakage issues ${ }^{4}$, and adjustment costs from resource re-allocations across sectors. It should also be noted that that the measurement of energy subsidies used here (accounting for just over half of the nationally efficient $\mathrm{CO}_{2}$ price in Saudi Arabia, for example) is not universally accepted, subsidies vary year-to-year with international fuel price volatility, and for practical purposes it may make more sense to reform the subsidies first, before implementing (more opaque) carbon pricing schemes.

The rest of the paper is organized as follows. Section 2 discusses a straightforward formula for the nationally efficient $\mathrm{CO}_{2}$ price and country-level data needed to implement it. Section 3 presents the main results. Section 4 introduces broader fiscal linkages. Section 5 offers concluding remarks.

\section{Defining and Measuring Nationally Efficient CO $\mathrm{C}_{2}$ Prices}

\section{A. Analytical Framework}

This sub-section discusses the welfare effects of carbon pricing in the presence of fuel taxes/subsidies and environmental externalities and (very basic) formulas to be estimated.

\section{(i) Assumptions}

A very simple comparative static model of fossil fuel use in a particular country is used where $X_{i}$ denotes the consumption of fuel, $p_{i}$ is the pre-tax supply price, and $i$ indexes four possible fuels - coal, natural gas, gasoline, and diesel used by road vehicles. ${ }^{5}$

\footnotetext{
${ }^{4}$ Usually leakage refers to partially offsetting increases in $\mathrm{CO}_{2}$ emissions in other countries without carbon pricing as energy-intensive, trade-exposed firms relocate away from countries with carbon pricing. More generally, some of the domestic air pollution benefits might be offset if coal production relocates to neighboring countries and the pollution crosses borders.

${ }^{5}$ Other fossil fuel products (e.g., diesel for farm and construction vehicles), are not included as their non- $\mathrm{CO}_{2}$ external costs have not been consistently estimated across countries, though their inclusion in the analysis would not have a major impact on the results.
} 
The fuel market prior to carbon pricing is shown in Figure 1. The height of the demand curve at any point is the benefit to fuel users from an extra unit of consumption (e.g., the benefit, net of travel time costs, from vehicle travel from an additional liter of gasoline), while the height of the supply curve reflects the costs (payments for labor, capital, energy, and resources to extract, transport, and process fuel, or import it) of producing an extra unit. The fuel demand curve is taken as linear over the relevant range for analytical convenience, which is a reasonable approximation given the scale of fuel reductions considered here. In addition, the fuel supply curve is taken to be perfectly elastic-allowing for an upward sloping supply curve would dampen fuel responses to carbon taxes, but perhaps only modestly in the longer run when supply curves tend to be relatively flat (e.g., Bovenberg and Goulder 2001).

Suppose there is a pre-existing excise tax of $t_{i}$ per unit on fuel $i{ }^{6}$ so the consumer fuel price is $p_{i}+t_{i}$ and fuel consumption is $X_{i 1}$. Compared with the zero-tax case, consumer (or fuel user) surplus is lower by trapezoid abed, while the government gains rectangle $a b c d$ in tax revenue, leaving a welfare cost of triangle bec (welfare costs, correctly measured to account for linkages with the broader fiscal system, are discussed later).

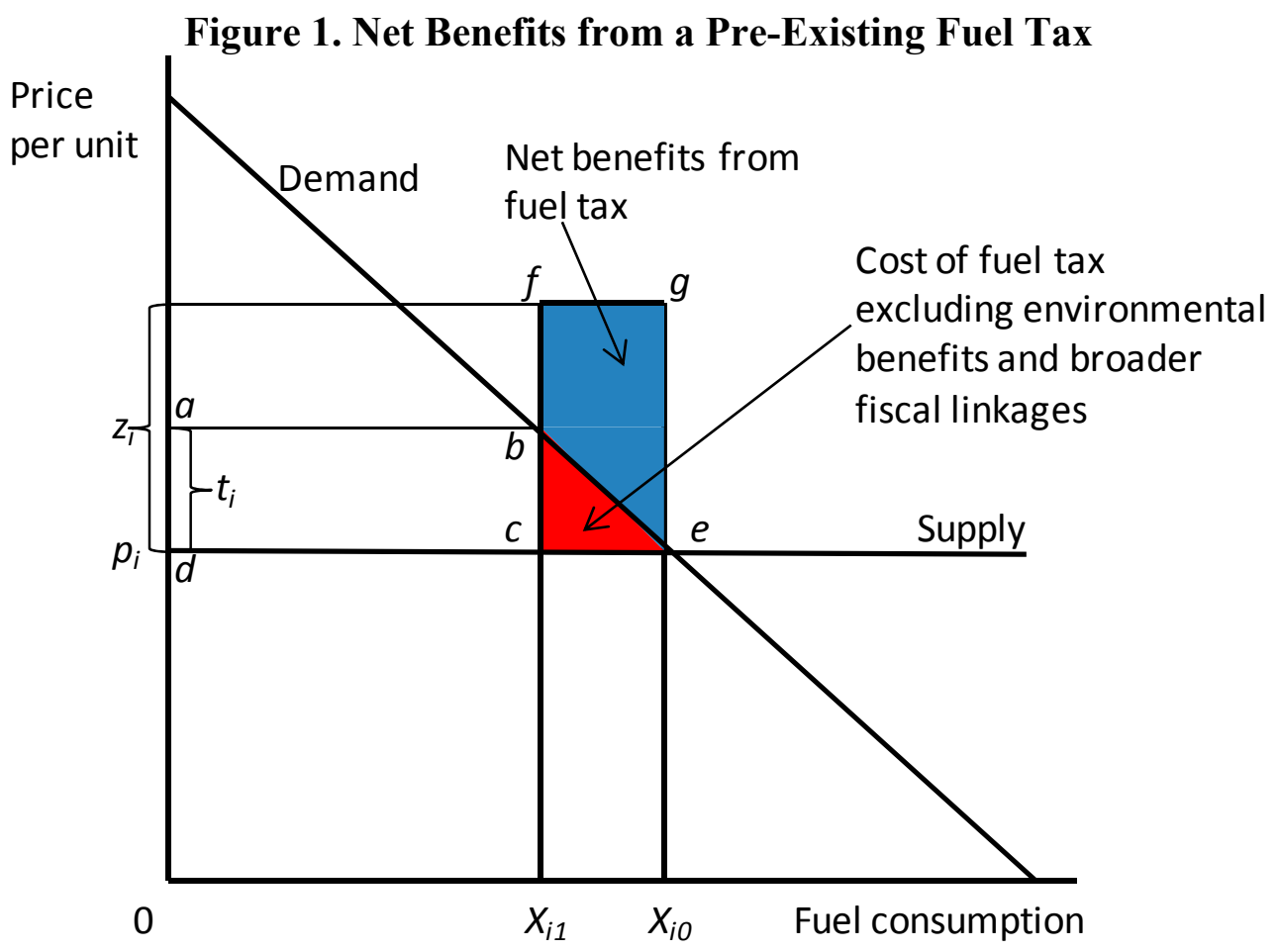

\footnotetext{
${ }^{6} t_{i}$ excludes any value added or general sales tax, as these taxes apply to consumer goods in general and therefore do not affect (to an approximation) affect the consumption of the fuel relative to other consumer products.
} 
Suppose also that fuel use is associated with a domestic environmental cost (i.e., excluding $\mathrm{CO}_{2}$ damages) per unit of $z_{i}$. For coal and natural gas these costs primarily reflect mortality risks to people exposed to the air pollution produced by combusting these fuels. For gasoline and road diesel, the costs also include those imposed on others from the extra road congestion, accident risk, and road damage due to the driving associated with additional fuel use. In measuring these externalities, account is implicitly taken of existing regulations, for example for emissions control technologies or vehicle safety, through their effects on observed emission rates, traffic fatalities, etc. Box 1 discusses further externalities from fuel use that (for various reasons) are excluded from co-benefit estimates used here, terms of trade effects, perhaps, being the most notable.

Accounting for these environmental costs, the fuel tax now produces domestic environmental benefits of rectangle $f g e c$ in Figure 1 and there is a net welfare gain, of trapezoid $f g e b-$ a positive welfare gain is more likely the larger are non- $\mathrm{CO}_{2}$ environmental costs per unit relative to the fuel tax.

In contrast if fuel is subsidized (which is common, for example, for petroleum in oil producing countries in the Middle East and North Africa where administered pricing causes large divergences between international and domestic prices) $t_{i}<0$ and there is a deadweight loss from the subsidy, the mirror image of triangle bec in Figure 1, between the supply and demand curve to the right of fuel consumption $X_{i 0}$. In addition, there is a further deadweight loss equal to the extra consumption caused by the subsidy, times the environmental damage per unit of fuel use.

\section{(ii) Nationally Efficient $\mathrm{CO}_{2}$ Prices}

Figure 2 shows the impact of a new carbon charge of $\tau$ per ton of $\mathrm{CO}_{2}$ emissions imposed on a fuel with non- $\mathrm{CO}_{2}$ environmental damages and pre-existing taxes and $\mathrm{CO}_{2}$ emissions factor (i.e., tons of emissions released per unit of fuel combustion) $e_{i}$. Trapezoid abcd reflects the impact of the charge on exacerbating the deadweight loss from the fuel tax but, for the case illustrated here, this is more than offset by the non- $\mathrm{CO}_{2}$ environmental benefits, leaving a net welfare gain of trapezoid efba. This trapezoid has average height $z_{i}-t_{i}-\tau e_{i} / 2$ and its base, the reduction in fuel use, is

$$
\text { (1) } X_{i 1}-X_{i 2}=-\frac{d X_{i}}{d \tau} \tau=-e_{i} \frac{d \tilde{X}_{i}}{d\left(p_{i}+t_{i}\right)} \tau=-e_{i} \eta_{i} \frac{X_{i 1}}{p_{i}+t_{i}} \tau
$$

In equation (1), $\eta_{i}=\left[d \tilde{X}_{i} / d\left(p_{i}+t_{i}\right)\right]\left[\left(p_{i}+t_{i}\right) / X_{i 1}\right]$ is a fuel price elasticity, where reminds us that the tax-inclusive prices of all fuels are changing simultaneously with carbon taxes, not just the own price, and the elasticity is evaluated at $\tau=0 . \eta_{i}$ would be the same as the own price elasticity of demand if there are no cross-price effects among fuels but will be smaller in size if fossil fuels are substitutes. 


\section{Box 1. Other Externalities from Energy Use}

There are a variety of other candidates for externalities associated with the production and use of fossil fuel energy that, for various reasons, are not taken into account here. Examples include:

Active living benefits from travel mode shifting. City-level studies (e.g., Woodcock et al. 2009) suggest there are substantial health benefits when individuals shift away from car trips to other travel modes involving physical exercise, including biking, walking, and walking to transit stops. However, much of the behavioral response to motor fuel taxes reflects other factors (e.g., longer run improvements in vehicle fuel economy, car pooling, combining car trips, using transit with minimal walking distance to stops) and people may internalize at least some of the health benefits in their travel mode decisions.

Environmental impacts from fuel extraction, storage, and transportation. Adverse side effects here include de-spoiling of the natural environment at mining and drilling sites, toxic releases from mine tailings and fuel processing wastes, leakage from fuel storage tanks, oil spills, etc. However, these types of external costs appear to be small in magnitude relative to external costs considered here (e.g., NRC 2009) and they are better addressed through other instruments than fuel taxes (e.g., double hull requirements for tankers, requirements that mined areas are returned to their natural state).

Energy security. The external costs of foreign energy dependence have always been opaque, and more so as expanding supplies of unconventional oil and gas reduce the share of global supplies coming from regions that might be viewed as unstable. In individual cases, policies to promote greater diversity in energy supply may make sense, but it is difficult to develop consistent, crosscountry estimates of taxes to correct for energy security concerns.

Indoor air pollution. The World Health Organization (WHO 2014) estimates that even more people die prematurely from inhaling indoor air pollution (e.g., fumes from fuel burning in cooking stoves) than from outdoor air pollution. But again, to what extent indoor air pollution-where the households causing pollution are mostly the ones affected by it - should be viewed as an external cost is not entirely clear. Moreover, there is a risk that high prices for taxed fossil fuels may cause switching to untaxed fuels (e.g., biomass, garbage) with equally, or perhaps worse, health effects. More pressing policies might include, for example, incentives for better ventilated stoves and clean fuel alternatives.

Terms of trade effects. If a group of countries collectively price carbon emissions this can result in lower international fuel prices and a transfer from fuel exporters to fuel importers - effectively, a worsening of the terms of trade for the former. From a national welfare perspective, this would represent a co-cost rather than a co-benefit for exporters. But these costs are not considered here as they are tricky to estimate - they depend, for example, on how many countries price carbon and how fuel supply (often in administered markets) responds. 


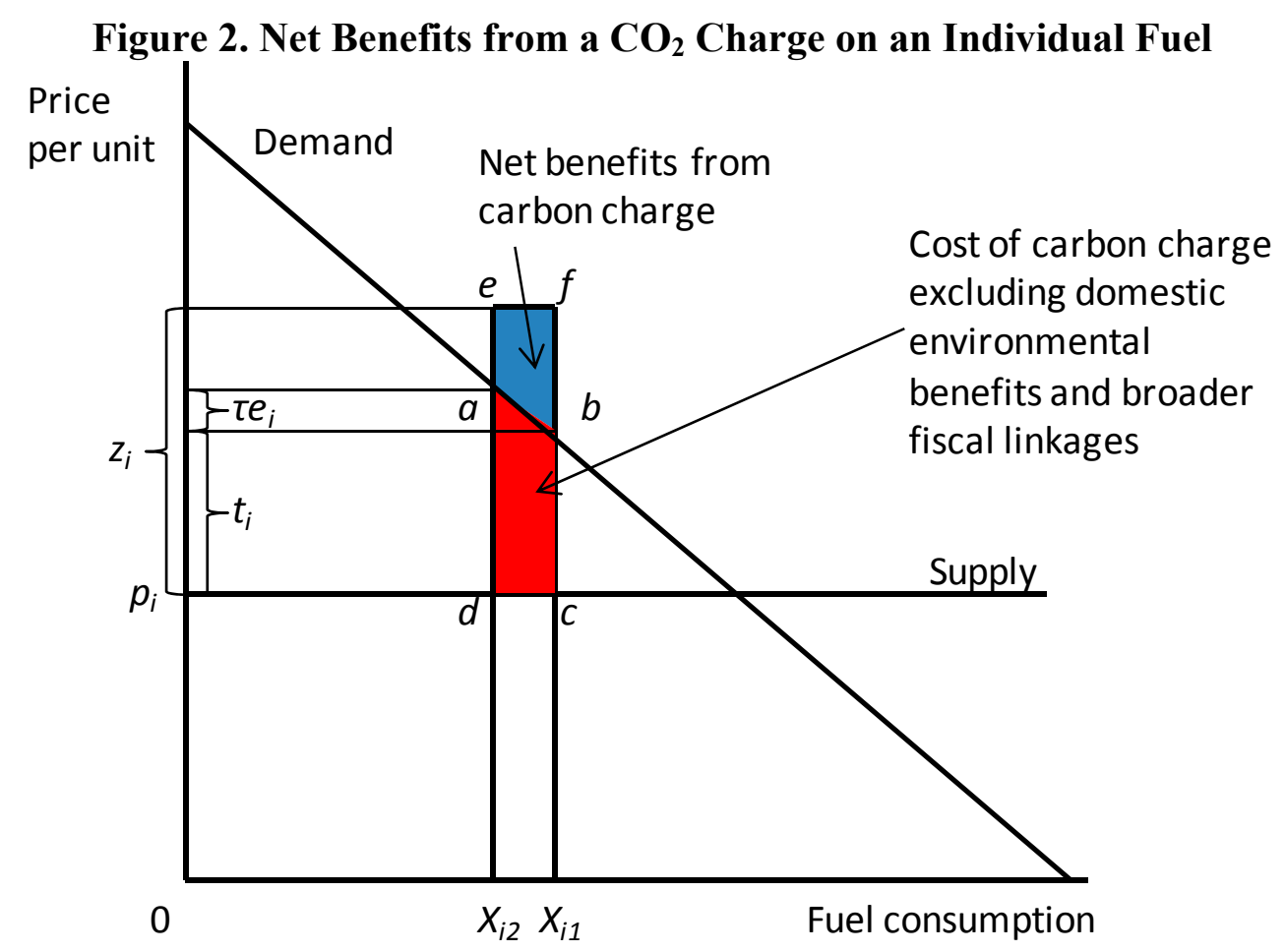

Aggregating over fuel markets (where quantity changes reflect both own- and crossprice effects), the total welfare change is:

$$
\text { (2) }-\sum_{i}\left(z_{i}-t_{i}-\frac{\tau e_{i}}{2}\right) \eta_{i} \frac{e_{i} X_{i 1}}{p_{i}+t_{i}} \tau
$$

Differentiating (2) with respect to $\tau$ ( $\eta_{i}$ is constant) gives the nationally efficient $\mathrm{CO}_{2}$ tax or price:

(3) $\tau^{*}=\frac{\sum_{i}\left(z_{i}-t_{i}\right) \eta_{i} s_{i} /\left(p_{i}+t_{i}\right)}{\sum_{i} e_{i} \eta_{i} s_{i} /\left(p_{i}+t_{i}\right)}$

where $s_{i}=e_{i} X_{i 1} / \sum_{i} e_{i} X_{i 1}$ is the (initial) share of $\mathrm{CO}_{2}$ emissions from fuel $i$ in total emissions. The nationally efficient carbon tax is higher:

- the larger are the non-internalized, non- $\mathrm{CO}_{2}$ external costs for fuels (relative to fuel prices);

- the greater the share of emissions accounted for by fuels with relatively high net external costs; and

- the greater the relative price responsiveness of fuels with relatively high net external costs.

However, a proportionate increase in all fuel price elasticities has no effect on the efficient tax-this increases the co-benefits and the $\mathrm{CO}_{2}$ reductions in the same proportion, but with no effect on co-benefits per ton of $\mathrm{CO}_{2}$ reduced. In other words, the efficient tax is independent of the overall responsiveness of the fossil fuel energy system to the tax (as 
reflected, for example, in the prospects for renewables and adoption of energy-saving technologies).

Equations (1) to (3) are applied using data discussed below, and used (in a spreadsheet) to infer nationally-efficient carbon prices, and their impacts on emissions, fuel use, and welfare.

\section{B. Data}

This subsection discusses baseline emissions and fuel data, fossil fuel externalities, and the price responsiveness of fuel use. The focus is on the top twenty $\mathrm{CO}_{2}$ emitting countries, henceforth "T20". The study year is 2010 (which avoids the need for data forecasting), the question asked being what would have been the nationally efficient $\mathrm{CO}_{2}$ price for T20 countries in that year.

\section{(i) Emissions and Fuel Data}

Energy-related $\mathrm{CO}_{2}$ emissions for 2010 (and GDP) are taken from IEA (2014). As indicated in Figure 3, China is the biggest emitter (26.8 percent of global emissions), followed by the United States (16.9), Russia (5.5), India (5.3), Japan (3.6), Germany (2.3) and Iran (1.9), while Poland (0.9) is the smallest emitter among the T20. The T20 together accounted for 80 percent of global energy-related $\mathrm{CO}_{2}$ emissions in 2010.

Also shown in Figure 3 is the $\mathrm{CO}_{2}$ intensity of the economy, measured in tons per $\$ 1,000$ of GDP - for a given carbon price and proportionate emissions reduction, the $\mathrm{CO}_{2}$ intensity indicates the scale of potential revenues and net economic benefits relative to the size of the overall economy. Most countries have a $\mathrm{CO}_{2}$ intensity of around 0.2 to 0.6 tons per $\$ 1,000$ of GDP, though China, Russia, India, and South Africa (all heavy coal users), and Iran and Saudi Arabia (intensive petroleum users), have $\mathrm{CO}_{2}$ intensities of around 1.0 or more.

Consumption of coal, natural gas, gasoline, and motor diesel by country for 2010 was also obtained from IEA (2014). 
Figure 3. $\mathrm{CO}_{2}$ Emission Shares and Intensity, 2010

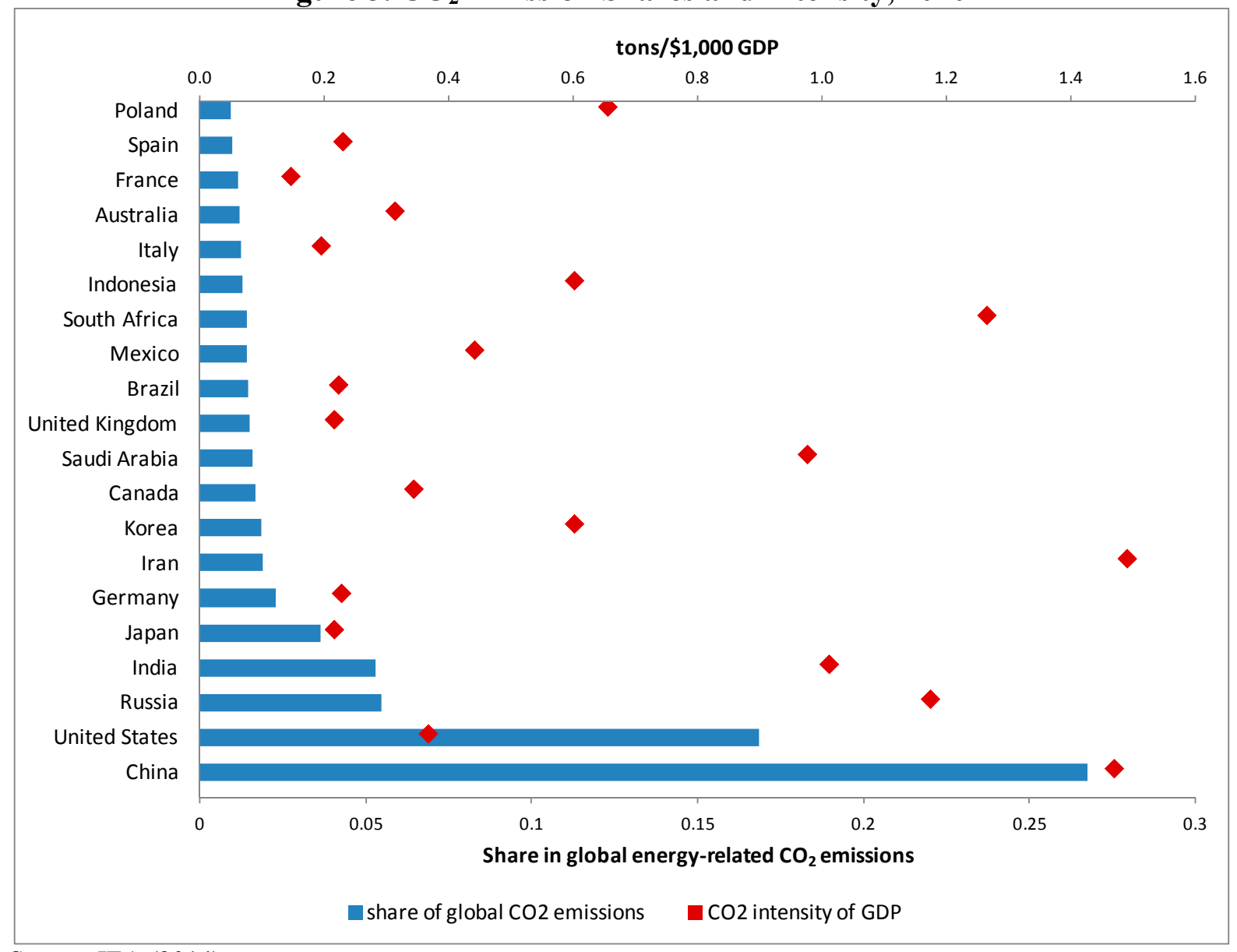

Source. IEA (2014).

Figure 4 shows the individual contribution of these fuels (using their carbon emissions factors - see below) to total emissions from the four fuels. Coal accounts for 75 percent or more of emissions in China, India, Poland, and South Africa but 20 percent or less in Brazil, France, Italy, Mexico, Saudi Arabia, and Spain. Natural gas accounts for around 20 to 60 percent of emissions in 15 countries, though only 2 to 3 percent in China and South Africa. Motor fuels combined mostly account for around 10 to 50 percent of emissions. 
Figure 4. Contribution of Fuels to $\mathrm{CO}_{2}$ Emissions, 2010

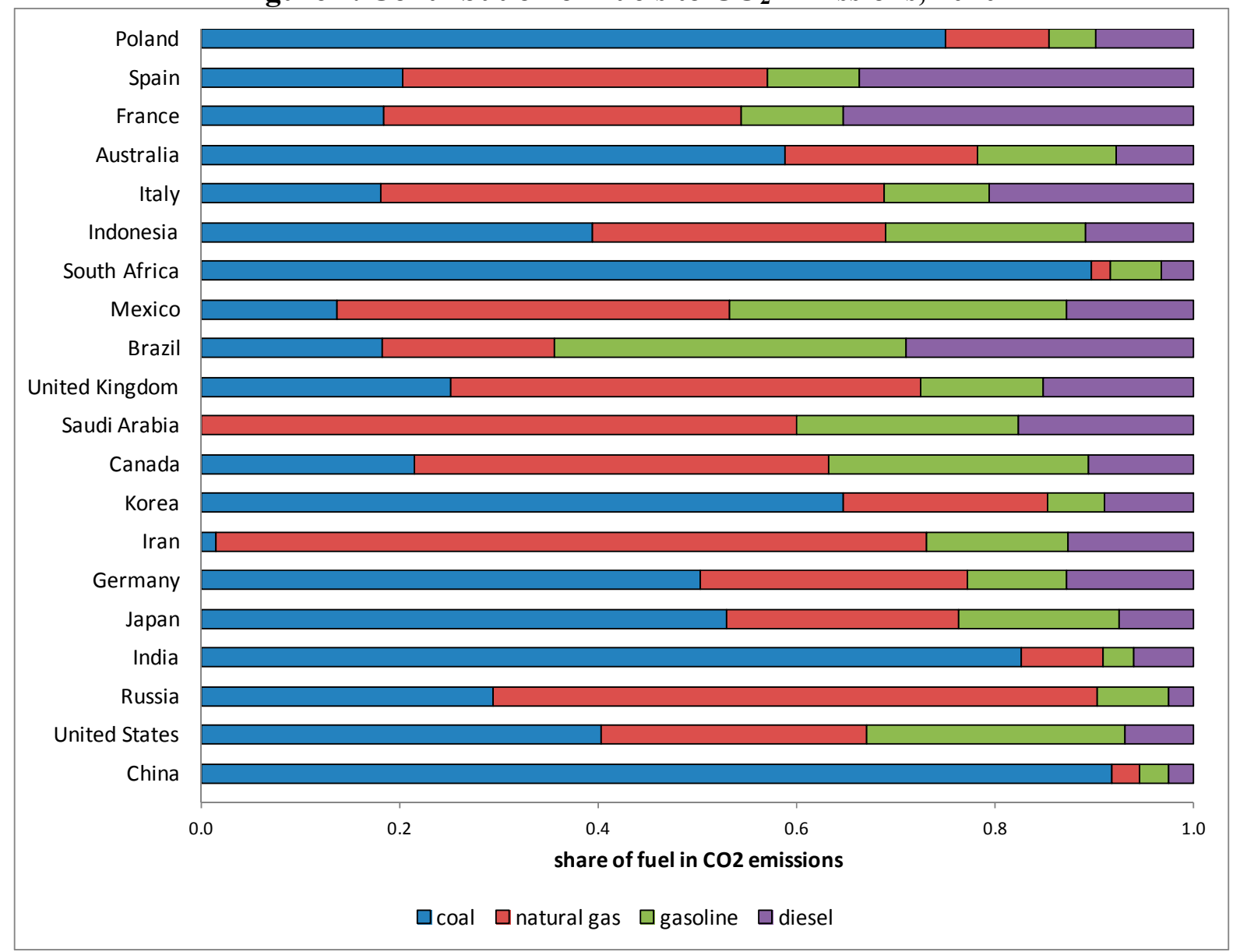

Source. IEA (2014).

Carbon emissions factors $\left(e_{i}\right)$ are taken from Parry et al. (2014) and show essentially no cross-country variations for a particular fuel, though per unit of energy, natural gas, gasoline, and motor diesel generate about 59 percent, 73 percent, and 78 percent respectively of the $\mathrm{CO}_{2}$ emissions per unit of coal energy. Carbon emissions factors and fuel use give the $\mathrm{CO}_{2}$ shares $\left(s_{i}\right)$.

Fuel user prices $\left(p_{i}+t_{i}\right)$ for 2010 by country are taken from an IMF database (see Clements et al., 2013, pp. 143-44). These prices are compiled from various sources including publicly available data, survey data, reporting from country authorities, and extrapolations from international reference prices. Fuel excise tax (or subsidy) rates $\left(t_{i}\right)$ are from OECD (2010) and Clements et al. (2013) — where not available publicly, these reflect estimated price gaps between demand and supply prices. 
Figure 5. Pre-Existing Fuel Taxes/Subsidies, 2010

$\left(\$\right.$ per ton $\left.\mathrm{CO}_{2}\right)$

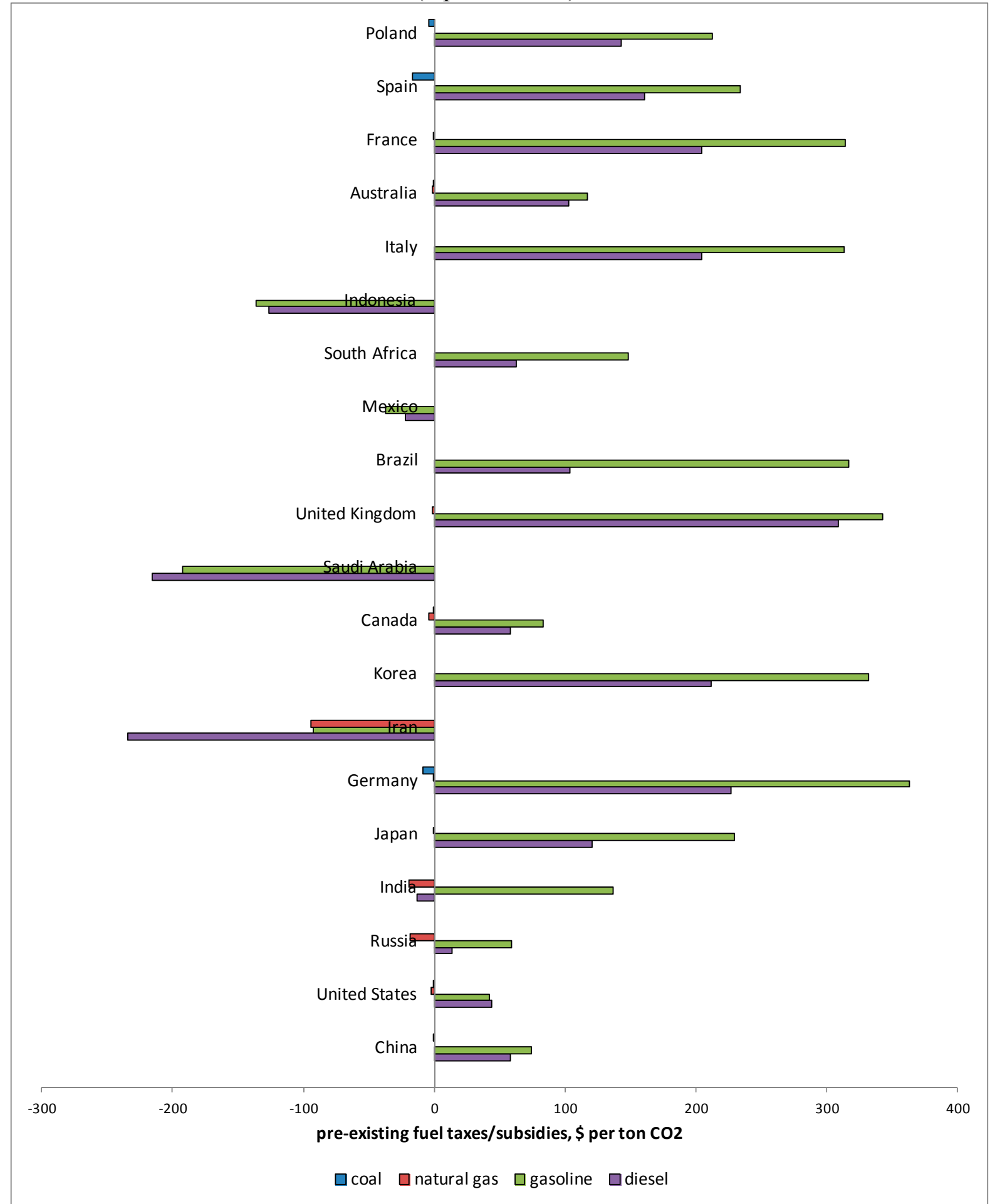

Source. Clements et al. (2013) and authors' calculations.

Note. Fuel taxes/subsidies per unit of fuels are divided by the fuel's emissions factor to express them in $\$$ per ton of $\mathrm{CO}_{2}$. Most countries do not significantly tax or subsidize coal or natural gas consumption. 
Figure 6. Non-COO $\mathrm{O}_{2}$ External Costs by Fuel, Net of Taxes/Subsidies, 2010 $\left(\$\right.$ per ton $\mathrm{CO}_{2}$ )

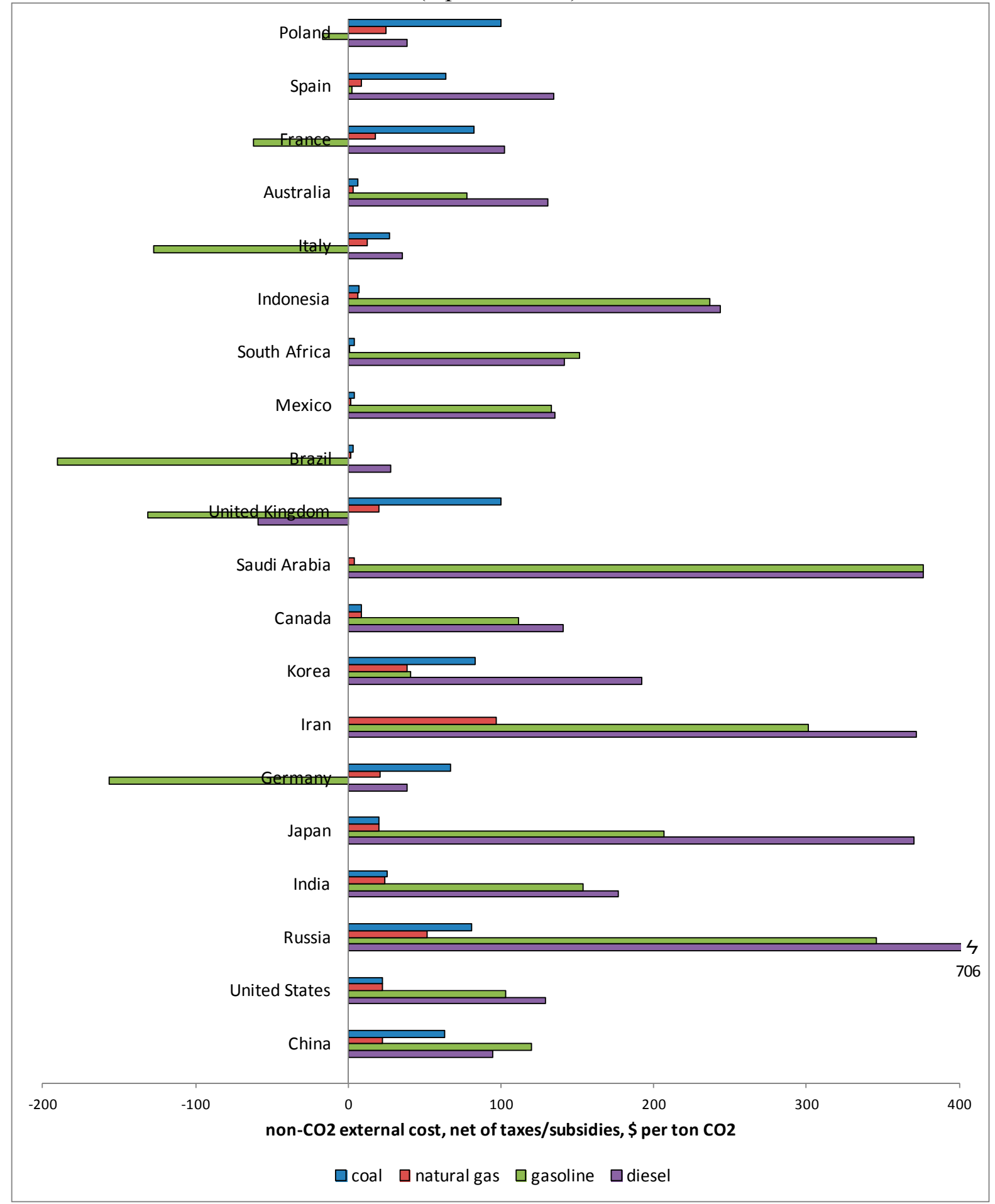

Source. Parry et al. (2014) and authors' calculations.

Note. Per unit external costs, net of fuel taxes/subsidies, are divided by the fuel's emissions factor to express them in $\$$ per ton of $\mathrm{CO}_{2}$. 
Figure 5 shows pre-existing taxes/subsidies in 2010, expressed per ton of $\mathrm{CO}_{2}$ (i.e., the tax/subsidy rate for a particular fuel divided by the carbon emissions factor for that fuel). There are no meaningful excises on coal and natural gas among the T20, and a handful of countries provide gas subsidies, for example, India (equivalent to $\$ 19$ per ton of $\mathrm{CO}_{2}$ ), Iran (\$95) and Russia (\$18). ${ }^{7}$ However, most countries levy sizeable motor fuel excises, equivalent to over $\$ 100$ per ton of $\mathrm{CO}_{2}$ for gasoline in 12 countries and for diesel (which is frequently tax favored relative to gasoline) ten countries. However, motor fuels are heavily subsidized in Indonesia, Iran, and Saudi Arabia, where gasoline subsidies were between $\$ 92$ and $\$ 193$ per ton of $\mathrm{CO}_{2}$ in 2010. An important caveat about the subsidies, however, is that to the extent they reflect differences in domestic and international fuel prices they vary from year to year with volatility in the latter. Moreover, the price-gap concept of a subsidy generally favored by economists is not accepted by all governments, especially if domestic prices recover domestic supply costs (the implications of ignoring subsidies are noted below).

\section{(ii) Externalities}

External costs $\left(z_{i}\right)$ are taken from a recent IMF study (Parry et al. 2014). Given the uncertainties and controversies involved in quantification (e.g., how to value health risks in different countries) these estimates are best viewed as a starting point for discussion though they are based on conservative assumptions (e.g., in regard to air emission rates at coal plants - see below). Methodological details are summarized in the Appendix (given that this paper does not refine the methodology). Here we go straight to the numbers, which are for 2010.

Figure 6 shows the external cost estimates by fuel net of any taxes or subsidiesthese estimates therefore reflect the gap between corrective taxes for non- $\mathrm{CO}_{2}$ externalities and existing fiscal policies - again expressed per ton of $\mathrm{CO}_{2}$ for that fuel. The external cost is simply the net external costs in Figure 6 plus the taxes (or less the subsidies) in Figure 5.

Non- $\mathrm{CO}_{2}$ externalities for coal are positive in all cases (because air pollution costs are positive while existing taxes are essentially zero), exceeding $\$ 50$ per ton of $\mathrm{CO}_{2}$ in eight cases, though they are moderate, for example, in South Africa, reflecting relatively low population exposure (given coastal proximities) and mortality risk values. ${ }^{8}$ Net external costs

\footnotetext{
${ }^{7}$ Since 2010 Iran substantially scaled back gas and petroleum subsidies though some of the price increases were later lost to inflation and exchange rate depreciation (e.g., Salehi-Isfahani 2011, IMF 2014). The implications of subsidy reform are noted under Figure 7 below.

${ }^{8}$ Broadly speaking, the air pollution damages for coal are in the same ballpark as those in a study by West et al. (2013). Their approach is based on an air quality model that disaggregates the world into 14 regions. For 2030 (in year \$2005) they estimate global average health co-benefits of \$50-380 per ton of $\mathrm{CO}_{2}$ reduced, with damages generally higher in developing than developed countries, and where the estimated range encompasses different scenarios for the valuation of health risks and pollution/health relationships. Nemet et al. (2010) review other studies, finding mean co-benefit estimates (in year 2008\$) of $\$ 44$ per ton of $\mathrm{CO}_{2}$ in developed countries and $\$ 81$ for developing countries.
} 
per ton of $\mathrm{CO}_{2}$ for natural gas are typically much smaller than for coal. ${ }^{9}$ For many countries, the next external cost from motor fuels is substantial, for example, over $\$ 100$ per ton of $\mathrm{CO}_{2}$ for diesel fuel for 14 countries (reflecting taxes undercharging of diesel fuel especially, due to unusually high air pollution damages, for Russia), though for five European countries and Brazil non- $\mathrm{CO}_{2}$ costs for gasoline are negative (reflecting taxes in excess of corrective levels). The nationally efficient $\mathrm{CO}_{2}$ price weights the net external costs from each fuel by their share in $\mathrm{CO}_{2}$ reductions (see below) implying, for most countries, a disproportionately large weight applied to coal's external costs.

\section{(iii) (Long-run) behavioral responses}

Estimating country-level fuel price elasticities $\left(\eta_{i}\right)$ is well beyond the scope of this paper as it would require developing a consistent methodology (for example based on crosssectional regressions, using a country-level data set) to develop these estimates. Instead, common elasticities across countries are assumed, taking a long-run perspective (after turnover of capital), based on the following discussion.

For the United States, a good starting point is the US Department of Energy's National Energy Modeling System (NEMS), which incorporates considerable detail on the energy sector and technology adoption, though the overall price responsiveness of fuel use in this model is viewed as conservative and tends to be somewhat smaller than implied by computable general equilibrium models. According to simulations from a variant of this model in Krupnick et al. (2010), the price elasticity for coal use in the United States (in response to a carbon tax, which takes into account the change in natural gas prices) is around -0.15. For comparison, the simple mean among eight studies of coal price elasticities (focusing on various OECD countries, China, and India) summarized in Trüby and Moritz (2011) is -0.28 . A coal elasticity of -0.25 is used for the benchmark calculations here (for all countries) - coal is relatively price inelastic, given the large sunk investments and very long lives of coal plants.

Natural gas tends to be more responsive to changes in its own price, given its frequent role in supplying peak period (as opposed to baseload) power, though (in countries where coal and gas compete) this is dampened as carbon pricing drives up the price of coal relative to gas. Here the natural gas elasticity is also assumed to be $-0.25 .^{10}$

\footnotetext{
${ }^{9}$ There are some exceptions to this. For example, per unit of energy air pollution damages from coal plants with control technologies in the United States are about 85 percent larger than for natural gas plants. However, carbon emission rates at coal plants are about 70 larger, therefore air pollution damages expressed per ton of $\mathrm{CO}_{2}$ are not very different for the two fuels (and gas receives a modest subsidy implying a still smaller difference in net external costs between the two fuels).

${ }^{10}$ For comparison, Liu (2004) estimates own price elasticities for natural gas (with no change in coal prices) of 0.24 to -0.36 .
} 
Numerous studies have estimated motor fuel (especially gasoline) price elasticities for different countries and the value assumed here, -0.5 for both gasoline and diesel, reflects, roughly speaking, a central value from the literature. ${ }^{11}$

\section{Results}

Benchmark estimates of nationally efficient carbon prices and their emissions impacts are first discussed, followed by a comparison of differentiated and uniform carbon pricing, and some sensitivity results.

\section{(i) Nationally Efficient $\mathrm{CO}_{2}$ Prices: Benchmark Estimates and Emissions Impacts}

Figure 7 shows calculations of nationally efficient $\mathrm{CO}_{2}$ prices for the $\mathrm{T} 20$ based on the above formulas and data. The average price for the T20 countries (with countries weighted by their emissions shares) is $\$ 57.5$ per ton of $\mathrm{CO}_{2}$ (all monetary figures are in US \$ 2010).

Also striking is the cross-country variation in the nationally efficient $\mathrm{CO}_{2}$ price$\$ 291$ per ton in Saudi Arabia (with terms of trade effects excluded), \$63 per ton in China, \$36 in the United States, \$11.5 in Australia and -\$23 in Brazil (i.e., Brazil on average overcorrects for co-benefits through pre-existing policies). The underlying determinants of these prices are discussed below.

Figure 8 shows the percent reduction in national, energy-related $\mathrm{CO}_{2}$ emissions from imposing nationally efficient $\mathrm{CO}_{2}$ prices, that is, the difference between estimated emissions that would have occurred with these prices in place in 2010, after full adjustment to these prices, and the actually observed emission levels in 2010. The figure also shows the contribution of individual fuels to those reductions.

\footnotetext{
${ }^{11}$ There is however significant variation among studies: for example, Sterner (2007) reports globally averaged (long-run) gasoline price elasticities of around - 0.7 (or larger, in magnitude), while individual country estimates in Dahl (2012) are closer to about -0.25 on average.
} 
Figure 7. Nationally Efficient $\mathrm{CO}_{2}$ Prices due to Domestic Co-Benefits, 2010

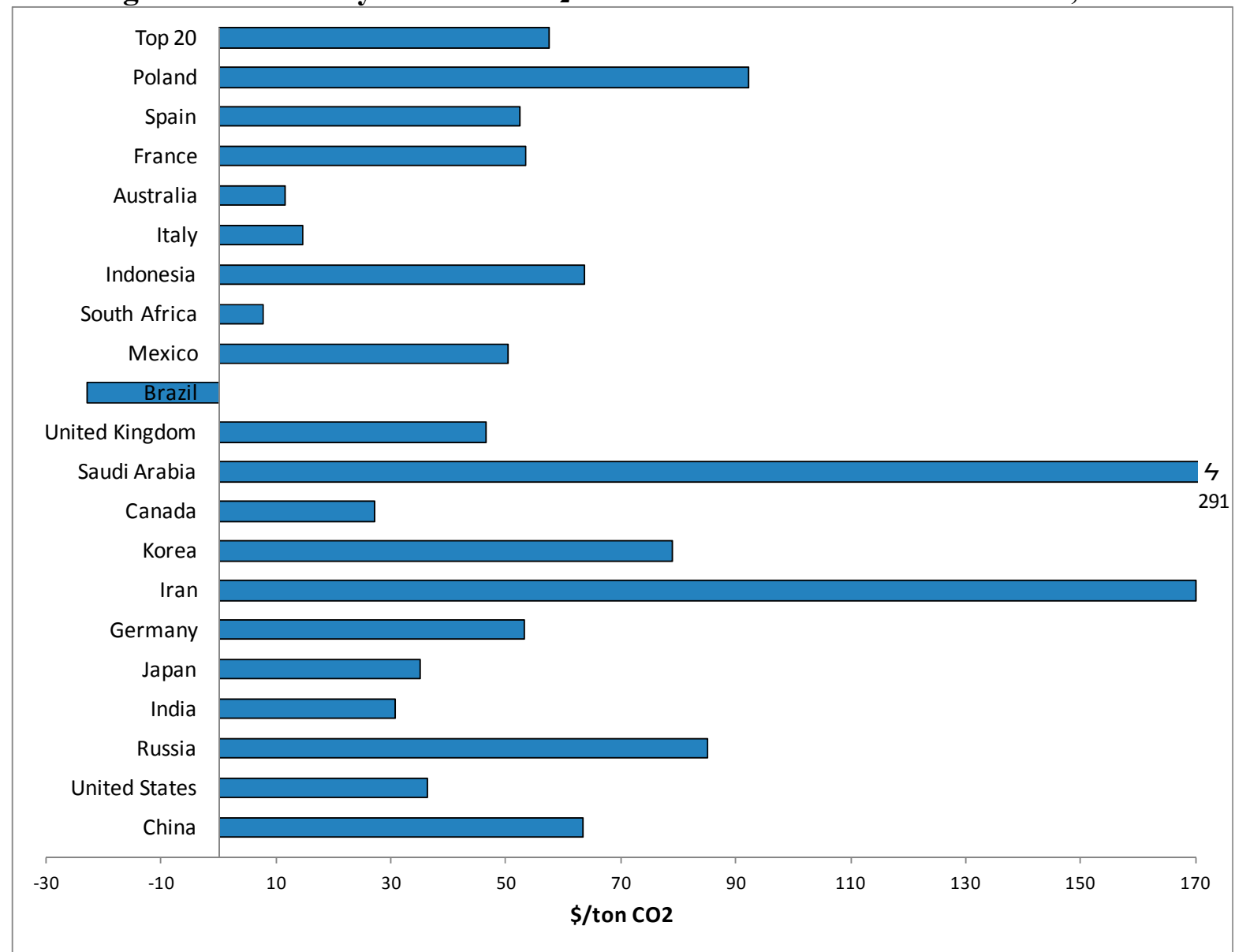

Source. Calculations using equation (3) and data discussed above.

Note. Figures show carbon prices that maximize domestic co-benefits (excluding climate benefits) net of climate mitigation costs (where costs do not account for broader fiscal linkages). Top 20 shows the price averaged across the top twenty emitters where individual country prices are weighted by their emissions shares. For Iran, calculations are based on fuel subsidies prevailing in 2010 which have since been reduced -if there had been so subsidies, the nationally efficient price for Iran would have been $\$ 52$ per ton of $\mathrm{CO}_{2}$. 
Figure 8. Emissions Reductions, and Sources of Reductions by Fuel Type, 2010

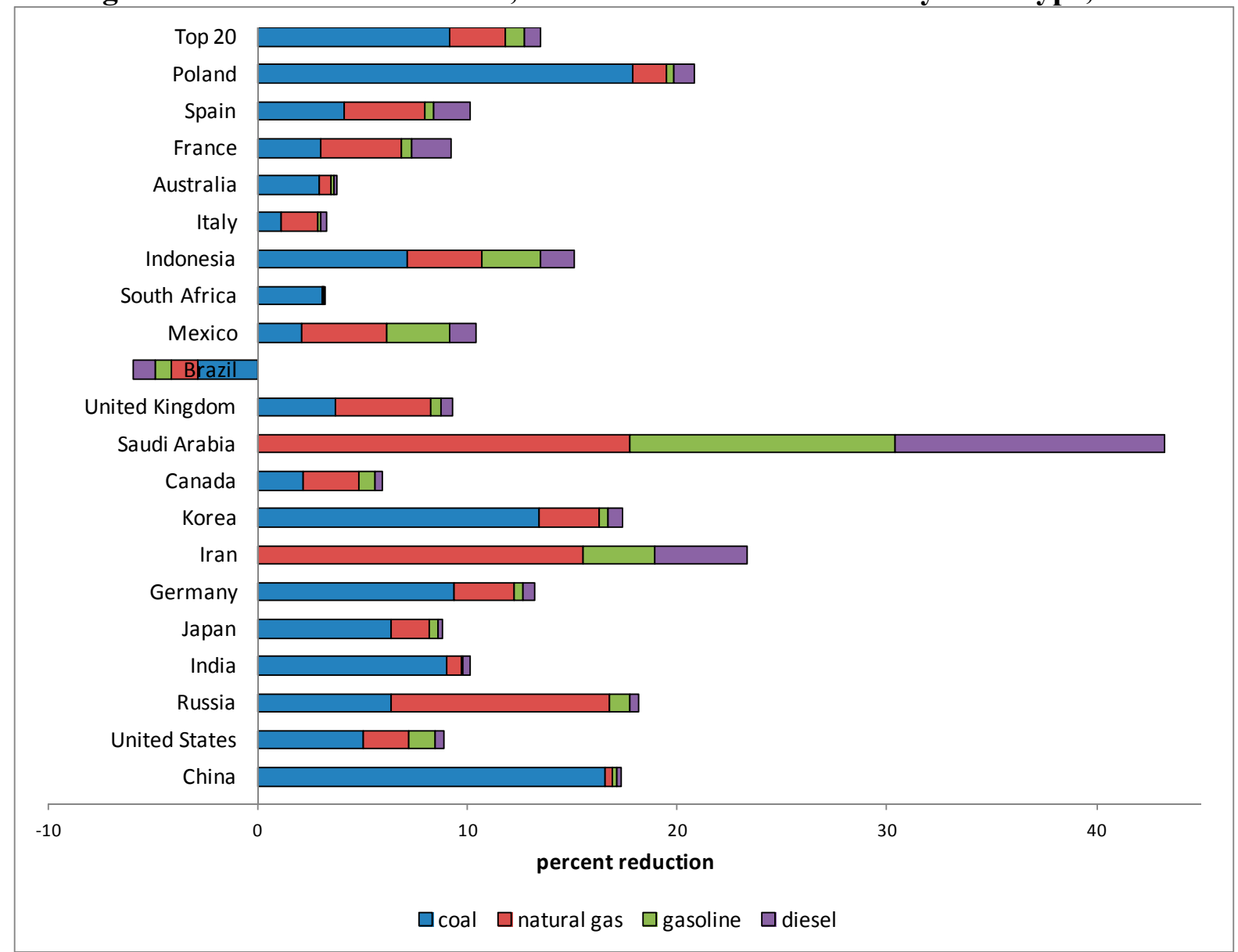

Source. Calculations using equation (4) and data discussed above.

Note. Figure shows estimated emissions reductions in 2010 that would have occurred if nationally efficient $\mathrm{CO}_{2}$ prices had been in place relative to actual emissions and the contribution of individual fuels to those reductions.

Total T20 emissions fall by 13.5 percent with nationally efficient $\mathrm{CO}_{2}$ pricing. However, there is a good deal of variation across countries - emissions fall by over 40 percent in Saudi Arabia (the outlier) and over 15 percent in China, Iran, Indonesia, Korea, Poland, and Russia, while they fall by less than 6 percent in Australia, Canada, Italy, and South Africa (and increase in Brazil given the nationally efficient price is negative).

For most countries the bulk of the $\mathrm{CO}_{2}$ reductions come from reduced coal use, because carbon pricing has a disproportionately large impact on coal prices (though this is dampened somewhat by the relatively low price responsiveness of coal compared with motor fuels) and coal has a high carbon emissions factor. For Saudi Arabia and Iran, the proportionate increase in motor fuel prices, and for gas in the case of Iran, is relatively large (given low, subsidized, prices for these fuels in 2010) and this leads to large $\mathrm{CO}_{2}$ reductions from these fuels.

Figure 9 returns to the nationally efficient carbon price, showing the underlying contribution to it from individual fuels (i.e., breaking out the four terms aggregated in equation (3)). For 11 countries, coal accounts for the majority of the nationally efficient 
carbon price. In Poland and China, for example, essentially all of the price reflects cobenefits from reduced coal use, because coal accounts for 86 and 95 percent of $\mathrm{CO}_{2}$ reductions respectively, and co-benefits ton are very large, $\$ 99$ and $\$ 64$ per ton of $\mathrm{CO}_{2}$ respectively (due to high air emissions rates and high population exposure to emissions).

Figure 9. Breakdown of Nationally Efficient Carbon Price by Fuel Type, 2010

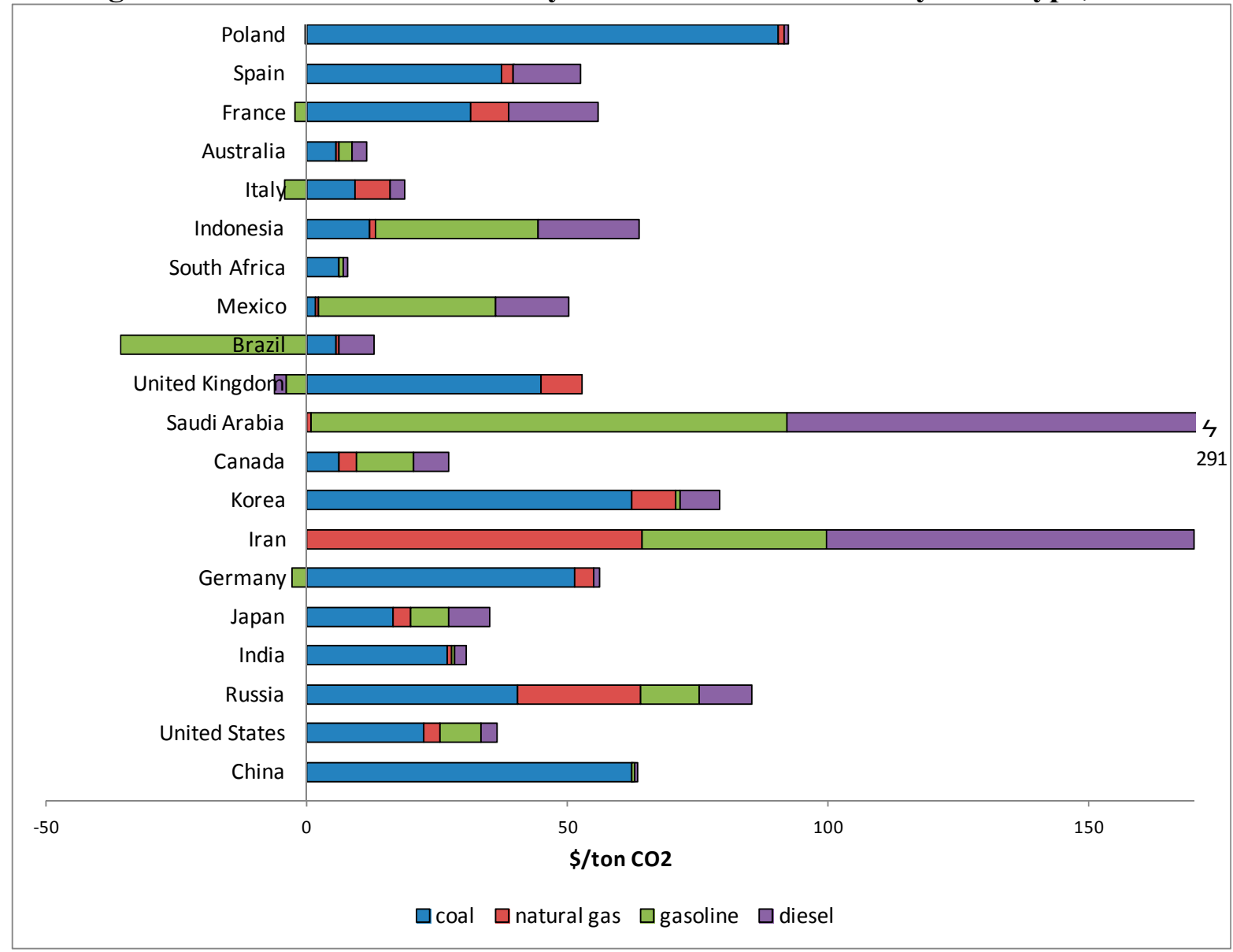

Source. Calculations using equation (3) and data discussed above.

In Italy and Brazil, co-benefits are more moderate as there is little use of coal, and motor fuel taxes in these countries are close to or exceed estimates of corrective taxes. Iran and Saudi Arabia do not use coal, and so all of the $\mathrm{CO}_{2}$ reduction comes from reduced use of motor fuels, and gas in Iran's case - for motor fuels in particular, there is a large gap between current taxes (which are negative for these countries) and corrective taxes, implying large cobenefits per ton of $\mathrm{CO}_{2}$ reduced. As already noted, not all countries agree with the price-gap measure of subsidies, but even if subsidies are excluded from the calculations, the nationally efficient $\mathrm{CO}_{2}$ price in Saudi Arabia, for example, is still large at over $\$ 130$ per ton of $\mathrm{CO}_{2}{ }^{12}$

\footnotetext{
${ }^{12}$ Corrective motor fuel taxes for Saudi Arabia are in the same ballpark as those, for example, for China (road congestion is less severe in Saudi Arabia, though Saudi Arabia has higher traffic accident externalities, and due to higher income, an hour of travel delay is valued more). A sizable portion of the $\mathrm{CO}_{2}$ reductions in Saudi
}

(continued...) 


\section{(ii) Net Benefits with Differentiated and Uniform Carbon Pricing}

Figure 10 shows the net economic benefits (excluding climate benefits and not accounting for broader fiscal interactions) from carbon pricing for the T20 countries (from equation (2)), expressed as a percent of GDP. Net benefits are shown under both nationally efficient $\mathrm{CO}_{2}$ pricing and when T20 countries all price emissions at the same rate ( $\$ 52$ per ton) to achieve the same emissions reduction (13.5 percent) in total for T20 countries as under nationally efficient pricing.

Under differentiated prices, net benefits average 0.20 percent of GDP across T20 countries. However, the gains are larger in China (0.70 percent of GDP) and Russia (0.76 percent of GDP), and much higher still in Saudi Arabia (3.09 percent).

Under the uniform pricing regime, net benefits for the T20 countries average 0.16 percent of GDP - thus there is a sizeable, though not dramatic, extra benefit ( 23 percent) from differentiated pricing over uniform pricing, in part because the nationally efficient prices in some of the big emitting countries are not that different from the uniform price. But there are some cases where uniform pricing substantially reduces net benefits for individual countries. For example, in Australia, Brazil, Italy, and South Africa the uniform price causes a net domestic cost, instead of a gain under (much lower) nationally efficient prices. Net benefits from Saudi Arabia are also reduced considerably for the opposite reason (the uniform price being far below the nationally efficient price).

\section{(iii) Sensitivity Analyses}

Table 1 reports results for the T20 countries as a whole, and China (the biggest emitter), for three sets of sensitivity analyses.

The first uses air pollution damages estimates for coal from Parry et al. (2014) that are based on current emissions rates averaged across all existing coal plants, including those with and those without air emissions control technologies. The above co-benefit estimates are based on the average emissions rates across only plants with control technologies. Which assumption is more appropriate is not entirely clear, given that current average emission rates are likely to be on a downward trend with greater future deployment of control technologies.

The higher emissions rate implies larger co-benefits from carbon pricing. In fact the nationally efficient $\mathrm{CO}_{2}$ price for the T20 as a group increases by about 50 percent to $\$ 85.5$ (and the associated emissions reductions rise to 17.6 percent), while the nationally efficient price for China, where deployment of emissions control technologies is less common than among the T20 as a whole, increases by 93 percent to $\$ 122.1$ per ton.

Arabia come from reduced use of natural gas (Figure 8) but, given the small co-benefits from reducing gas, this contributes minimally to the nationally efficient price in Figure 9. 
Figure 10. Net Benefits from Nationally Efficient and Uniform Pricing, 2010

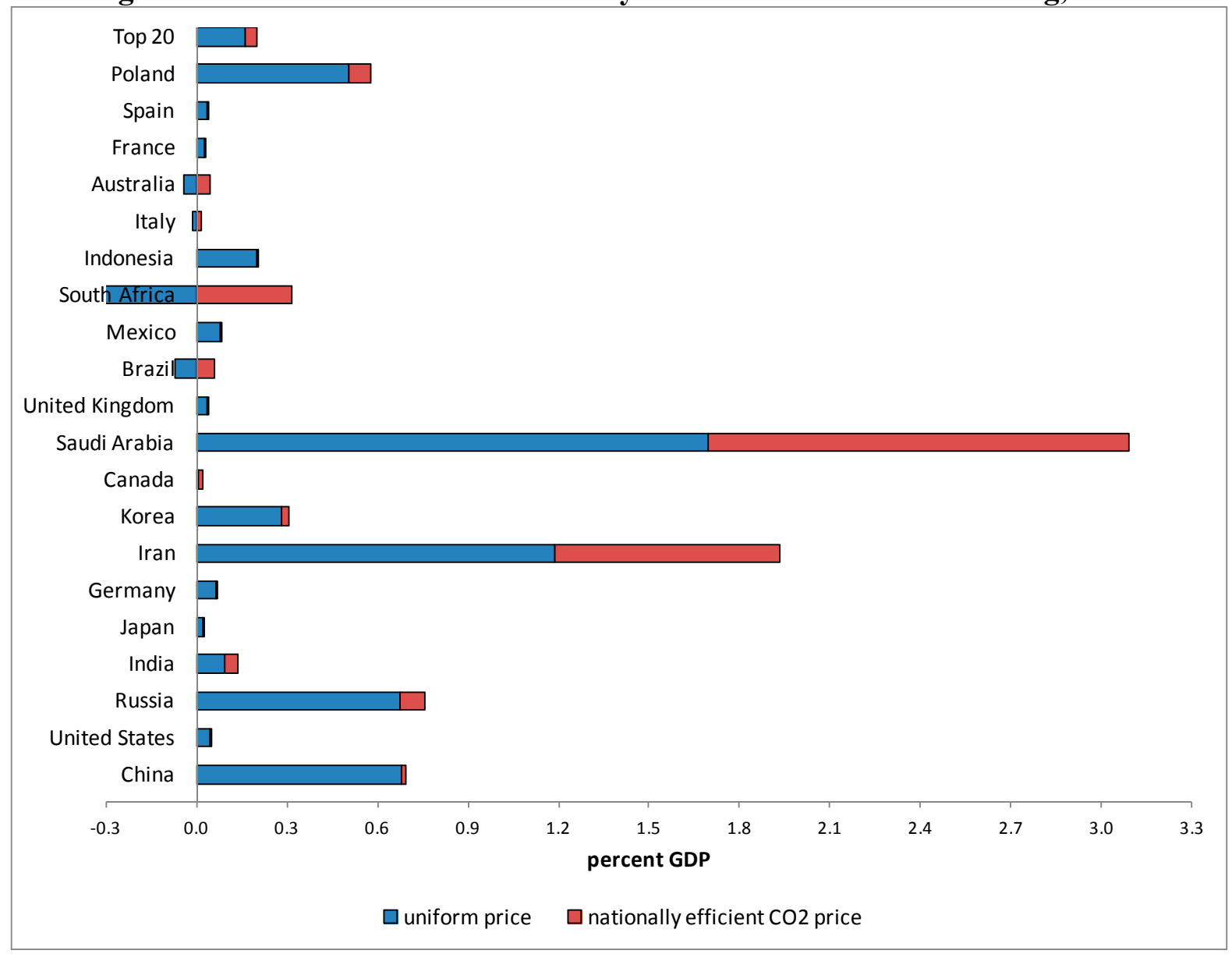

Source. Calculations using equation (2) and data discussed above.

Note. Net benefits are domestic environmental benefits less $\mathrm{CO}_{2}$ mitigation costs reflecting behavioral responses, such as power generators using cleaner but more expensive fuels and motorists driving less than they would otherwise prefer.

Adjusting all fuel tax elasticities by the same proportion has no effect on the nationally efficient $\mathrm{CO}_{2}$ price (see above), though the emissions reductions from these prices obviously vary. For the T20 group of countries, $\mathrm{CO}_{2}$ emissions reductions vary between 7.1 and 19.3 percent as all fuel price elasticites are reduced and increased by 50 percent. Raising the price elasticities for coal and natural gas up to those for motor fuels (while holding those for motor fuels fixed) also increases the emissions reductions considerably. The nationally efficient prices for the T20 fall modestly in this simulation however (to $\$ 52.3$ per ton) - on average, the co-benefits per ton of $\mathrm{CO}_{2}$ associated with reducing coal and natural gas are less than the co-benefits per ton from reduced use of motor fuels. 
Table 1. Sensivity Analysis

\begin{tabular}{|c|c|c|c|}
\hline & $\begin{array}{c}\text { nationally efficient } \\
\text { carbon price } \\
\$ / \text { ton } \mathrm{CO}_{2}\end{array}$ & $\begin{array}{l}\text { percent reduction } \\
\text { in } \mathrm{CO}_{2}\end{array}$ & $\begin{array}{l}\text { net benefits } \\
\text { percent of GDP }\end{array}$ \\
\hline \multicolumn{4}{|l|}{ Baseline case } \\
\hline Top 20 Emitters & 57.5 & 13.5 & 0.20 \\
\hline China & 63.4 & 17.3 & 0.70 \\
\hline \multicolumn{4}{|c|}{ Coal air pollution damages based on average emissions across all plants (rather than only those with controls) } \\
\hline Top 20 Emitters & 85.5 & 17.6 & 0.39 \\
\hline China & 122.1 & 25.2 & 1.95 \\
\hline \multicolumn{4}{|l|}{$\begin{array}{l}\text { Behavioral responses to carbon pricing } \\
\text { all fuel elasticities increased } 50 \text { percent }\end{array}$} \\
\hline Top 20 Emitters & 57.5 & 19.3 & 0.28 \\
\hline China & 63.4 & 24.8 & 1.00 \\
\hline all fuel elasticities reduced 50 percent & 57.5 & 7.1 & 0.11 \\
\hline Top 20 Emitters & 63.4 & 9.1 & 0.36 \\
\hline \multicolumn{4}{|l|}{ China } \\
\hline \multicolumn{4}{|c|}{ coal and natural gas elasticities increased to those for motor fuels } \\
\hline Top 20 Emitters & 52.3 & 22.3 & 0.30 \\
\hline China & 63.0 & 31.1 & 1.24 \\
\hline \multicolumn{4}{|l|}{$\begin{array}{l}\text { Non-carbon external costs } \\
\text { increased } 50 \text { percent }\end{array}$} \\
\hline Top 20 Emitters & 85.7 & 17.6 & 0.36 \\
\hline China & 95.7 & 22.1 & 1.34 \\
\hline \multicolumn{4}{|l|}{ halved } \\
\hline Top 20 Emitters & 29.3 & 7.7 & 0.08 \\
\hline China & 31.1 & 10.6 & 0.21 \\
\hline
\end{tabular}

Finally the results are obviously sensitive to different assumed values for non- $\mathrm{CO}_{2}$ external costs. The nationally efficient $\mathrm{CO}_{2}$ prices for the T20 countries as a whole vary between $\$ 29.3$ and $\$ 85.7$ per ton as these damage values are reduced and increased by 50 percent. If anything the non- $\mathrm{CO}_{2}$ damage values used in the baseline estimates are likely on the low side (e.g., due to conservative assumptions about coal emission rates). 


\section{Fiscal Considerations}

After noting how much revenue is raised from carbon pricing, this section discusses how fiscal linkages influence the net economic benefits of carbon pricing policies.

As indicated in Figure 11, nationally efficient carbon pricing policies can raise substantial amounts of revenue - above 6 percent in China, Russia, Iran, and Saudi Arabia. The average for the T20 countries is 1.9 percent of GDP, which is still very substantial, though reflects the large influence of the United States (where carbon pricing revenues are 1.1 percent of GDP), given that country-level revenues are weighted here by country shares in T20 GDP.

Broader taxes in the fiscal system (taxes on personal and corporate income, payrolls, and consumption) burden the economy by creating two sorts of distortion to economic activity. First, the tax system distorts factor markets, thereby reducing the overall level of economic activity. By lowering the net of tax return from working, and therefore discouraging labor force participation, effort on the job, and so on, taxes on labor income reduce work effort below levels that would otherwise maximize economic efficiency. Similarly, by lowering the net of tax returns on investments in (physical and human) capital, these taxes reduce capital accumulation below economically efficient levels. Second, taxes also distort the composition of economic activity, most obviously by encouraging more activity in the informal sector (where productivity tends to be lower than in the formal sector), and also causing a bias towards other tax-sheltered activities or goods (e.g., tax preferences for owner occupied housing cause people to spend more on housing and less on ordinary goods than they would otherwise prefer, lowering the value of their purchasing power). Over the last two decades, public finance economists have emphasized the critical importance of considering the full range of behavioral responses - the composition as well as the level effect - when evaluating the economic costs of the tax system (e.g., Gruber and Saez 2002, Feldstein 1995, 1999, Saez et al. 2010).

Carbon taxes (or tax-like instruments) interact with the broader fiscal system in two important ways. First, large efficiency gains are generated when revenues are used to lower other distortionary taxes (or for other purposes producing comparable gains in economic efficiency) - this is termed the 'revenue-recycling' effect. Second, however, higher energy prices tend to compound the distortions from taxes in factor markets by reducing (via a contraction in overall economic activity) work effort and capital accumulation. 
Figure 11. Revenue from Nationally Efficient Carbon Prices, 2010

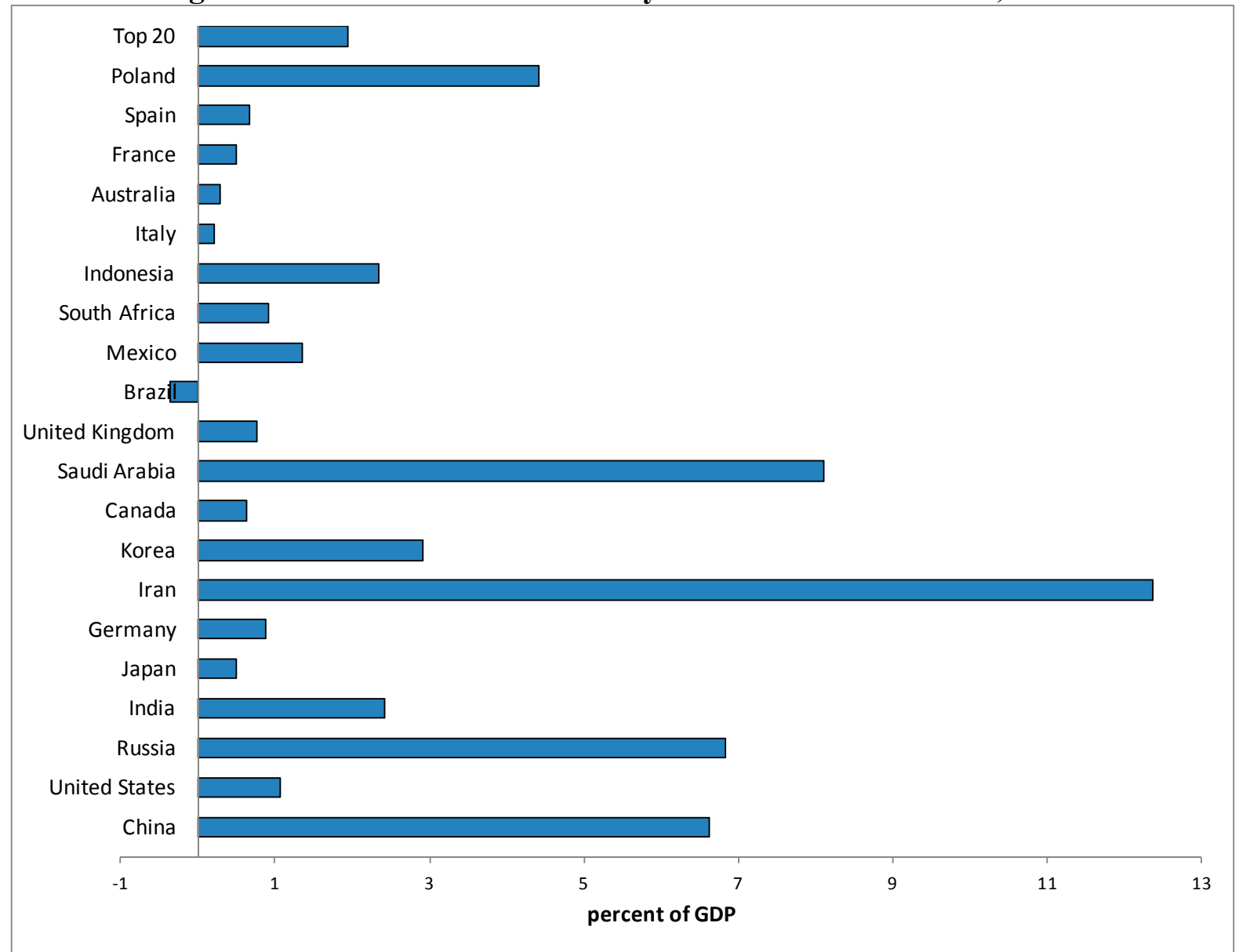

Source. Calculations using above equations and data.

Note. The average for the top 20 emitters weights countries revenue to GDP ratio by their shares in total GDP (which raises the influence of countries with high GDP like the United States). Revenue here is measured simply by the $\mathrm{CO}_{2}$ emissions price times $\mathrm{CO}_{2}$ emissions, accounting the price-induced reduction in emissions, but ignoring interactions with other tax bases (e.g., for pre-existing fuel taxes). 
Up to a point (i.e., so long as the reduction in the base of the carbon tax is not too great), there can be a net economic gain from these two effects (the revenue-recycling effect dominates the tax-interaction effect). Basically, this is because cutting broader taxes helps to reduce distortions both to the level, and the composition, of economic activity, while although higher energy prices can lower the level of economic activity they do not, to an approximation, worsen distortions in the composition of economic activity. ${ }^{13}$

However, the more important point is that if revenue opportunities are not exploited, for example allowances are freely allocated in a trading system or carbon tax revenues are earmarked for spending projects that do not significantly increase economic efficiency, then fiscal linkages considerably increase the costs of carbon pricing policies - perhaps by enough to more than offset the gains from pricing environmental damages! This follows because such polices fail to counteract the adverse tax-interaction effect with revenue-recycling benefits.

Formulas from the literature ${ }^{14}$ are applied here to adjust the net benefits from nationally efficient carbon pricing from the previous section to account for the two linkages with the broader fiscal system, comparing cases with recycling benefits (revenues are used to cut other distortionary taxes) and with no recycling benefit (revenues are returned in lumpsum transfers). The calculations are inescapably very crude, given the scarcity of empirical work on the economic costs of the broader tax system, at least beyond the United States. The calculations assume that - for each country - using revenue to reduce other taxes results in an efficiency benefit of $\$ 0.25$ per $\$ 1$ of revenue recycled and that 60 percent of this gain comes from increases in the level of economic activity and 40 percent from reduced distortions to the composition of economic activity. ${ }^{15}$

Figure 12 summarizes the results. The orange bars simply reproduce the net benefits from nationally efficient (i.e., differentiated) carbon pricing from Figure 8.

The green bars in Figure 12 indicate the additional gain from fiscal linkages when revenues are used to cut other taxes (i.e., the revenue recycling benefit less the cost of the tax-interaction effect). For the T2 0 countries as a whole, net benefits double to 0.33 percent

\footnotetext{
${ }^{13}$ This follows if the energy intensity of tax-favored sectors (like housing) is not too different from that for the economy as a whole (Parry and Bento 2000), or if the informal sector largely supplies low-energy-intensive goods and services (Bento et al. 2012). Some early papers (e.g., Bovenberg and Goulder 1996, Parry 1995) suggested that the revenue-recycling benefit falls short of the tax-interaction effect, implying that fiscal interactions lower the net benefits of carbon tax swaps. However, these studies substantially understate revenue recycling benefits as they do not capture distortions to the composition of economic activity caused by the broader tax system (see Parry and Bento 2000).

${ }^{14}$ See Parry and Williams (2010), pages 9-10 (after simplifying to one household group). Similar formulas have been shown to yield results that are approximately consistent with detailed numerical models (e.g., Goulder et al. 1999).

${ }^{15}$ The total private sector benefit (the $\$ 1$ transfer plus the gain in economic efficiency) is $\$ 1.25$. These figures are based on an assessment of US evidence in Parry and Williams (2010).
} 
of GDP - for some countries the proportionate increase in net benefits is much greater still (e.g., more than 200 percent in eight countries). The bottom line from these, albeit very course, calculations is that fiscal considerations appear to significantly reinforce the net benefits from carbon pricing if revenues are used to substitute for other distortionary taxes.

On the other hand, the grey bars in Figure 12 suggest that carbon pricing produces net economic costs - not net benefits-when there are no recycling benefits. That is, the economic costs from the tax-interaction by itself (when it is not counteracted by the revenue recycling benefit) outweigh the gains from pricing co-benefits. This underscores the importance, long emphasized in the literature (e.g., Parry et al. 1999) of implementing carbon pricing as part of a tax shift, rather than an increase in the tax burden-unless the extra government spending yields gains in economic efficiency that are comparable to those from reducing distortionary taxes.

\section{Conclusion}

This paper provides calculations of nationally efficient $\mathrm{CO}_{2}$ prices, that is, prices to reflect domestic externality benefits (net of any internalization through fuel taxes/compounding through subsidies and excluding climate-related benefits) for reducing use of coal, natural gas, and motor fuels, for the top twenty $\mathrm{CO}_{2}$-emitting countries.

On average these prices are quite high, $\$ 57.5$ per ton of $\mathrm{CO}_{2}$, suggesting that (most) high-emitting countries need not wait on global coordination to move ahead with carbon pricing programs because the domestic environmental benefits (dominated, in many cases, by reductions in pollution-related deaths) exceed the mitigation costs. Nationally efficient $\mathrm{CO}_{2}$ prices vary substantially across countries however (with population exposure to coal's air emissions, road congestion, health risk valuation, pre-existing fuel taxes/subsidies, etc.), raising a question mark over the desirability of price harmonization measures (like linking of trading systems). Moreover, a key finding from prior literature on carbon pricing remains robust - if carbon pricing revenues are overly used for low-value purposes (or revenues are forgone by free allocation in trading systems) the overall welfare impacts can be negative rather than positive. Ideally, carbon pricing is part of a broader tax shifting operation that lowers other taxes in the fiscal system with the new revenues from carbon taxes (or allowance auctions). 
Figure 12. Net Benefits from Carbon Pricing Accounting for Fiscal Linkages, 2010

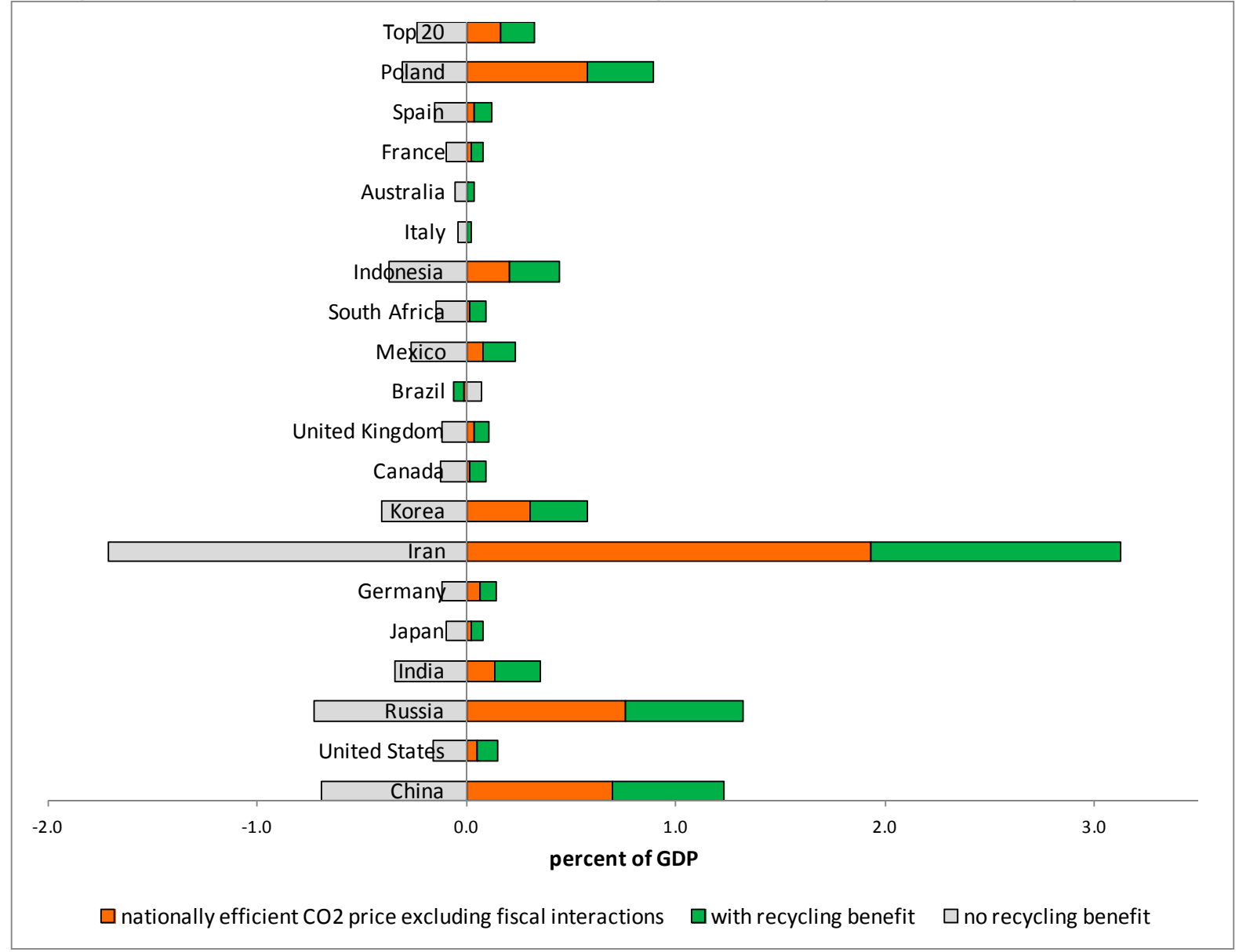

Source. Net benefits from Figure 10 for the nationally efficient price are adjusted for fiscal linkages based on formulas in Parry and Williams (2010) and assuming an efficiency benefit of $\$ 0.25$ per $\$ 1$ of revenue used to reduce distortionary taxes with 60 percent of this benefit due to increases in the level of economic activity and 40 percent from reduced distortions to the composition of economic activity.

Note. The orange bars, replicated from Figure 8, show the net benefits from nationally efficient pricing when linkages with the broader fiscal system are (incorrectly) ignored. The green bars indicate net efficiency benefits from fiscal interactions when revenue is used to cut other distortionary taxes. The grey bars show net efficiency costs from fiscal interactions in the absence of recycling benefits. 


\section{Appendix: Methodology Underlying non- $\mathrm{CO}_{2}$ External Damages}

This Appendix discusses the valuation of air pollution damages from stationary sources, and externalities from motor vehicles, that underlie the co-benefit estimates used above.

Air Pollution from Coal and Natural Gas. The key air pollutant from a public health perspective is fine particulate matter $\left(\mathrm{PM}_{2.5}\right.$, with diameter up to 2.5 micrometers), which is small enough to penetrate the lungs and bloodstream. $\mathrm{PM}_{2.5}$ can be emitted directly during fuel combustion, or formed indirectly through chemical reactions in the atmosphere involving sulfur dioxide $\left(\mathrm{SO}_{2}\right)$ and nitrogen oxide $\left(\mathrm{NO}_{\mathrm{x}}\right)$ emissions. ${ }^{16}$

Parry et al. (2014) assess damages from these pollutants for coal plants by first estimating 'intake fractions' - the fraction of these emissions that are inhaled by exposed populations as $\mathrm{PM}_{2.5}$. They begin with state-of-the-art estimates (Zhou et al. 2006) of these fractions for the average coal plant in China, where these estimates account-given that pollution from tall smokestacks can be transported great distances - for exposure to people living up to 2,000 km from plants. Parry et al. (2014), extrapolate intake fractions to other countries depending on the number of people living at different distance classifications from the average coal plant in that country relative to the number of people living in those distance classifications in China. This is done by mapping data on the location of coal plants (in over 100 countries) to very granular, spatial population data. ${ }^{17}$ Note that some of the air pollution deaths will be across the border (given the long-range transport of pollution from tall smokestacks) so not all of the co-benefits from carbon pricing are strictly national benefits.

Intake fractions are then linked to mortality risks. Baseline mortality rates are estimated for diseases (e.g., lung cancer, heart disease) whose prevalence is potentially increased by pollution exposure, using data on age structures for each country and regional average mortality rates by age/type of disease estimated in the Global Burden of Disease (GBD) project. ${ }^{18}$ These baseline mortality rates are then scaled by intake fractions and evidence (again from GBD) on how the relative risk for each disease increases with the rate at which pollution is inhaled, to give health impacts per ton of emissions for the three air pollutants.

\footnotetext{
${ }^{16}$ The possible global cooling benefits of particles, which can reflect sunlight, are not considered here.

${ }^{17}$ The main limitation of this approach is that it assumes emissions in another country have the same impact on ambient pollution concentrations at different differences from a coal plant as in China. This will not be the case, for example, if wind speeds and directions are very different in the other country compared with average conditions in China. However, studies suggest population exposure is usually a far more important determinant of health damages than differences in meteorology (e.g., Zhou et al. 2006). Moreover, Parry et al. (2014) report some cross-country checks from a regional air quality model (that does take meteorology into account) suggesting the extrapolations may not be too far off in most cases and that there is no systematic pattern to the direction of bias.

${ }^{18}$ See Burnett et al. (2013). Baseline mortality rates vary substantially across countries—-for example, rates are relatively low in Sub-Saharan Africa where people are less likely to survive long enough to die from diseases that can be exacerbated by pollution.
} 
Health risks are then monetized. There is solid empirical evidence suggesting that people's willingness to pay to reduce health risk $^{19}$ rises with real income-according to a meta analysis of several hundred stated preference studies by OECD (2012), each onepercent increase in real income increases mortality values by 0.8 percent. Using this statistic, relative per capita income, and a starting value for the average OECD country ( $\$ 3.7$ million per premature death, updated from OECD 2012), Parry et al. (2014) infer mortality values for all countries, and hence damages per ton of emissions.

Finally, environmental damages can be expressed per gigajoule (GJ) of coal energy using country-level estimates of emissions rates per $\mathrm{GJ}^{20}$ - that is, the damage per GJ is the emission rate, times the damage per ton of emissions, summed over the three pollutants. The damage estimates underlying the main results below are conservatively based on average emission rates at coal plants currently employing control technologies. Using national average emission rates produces higher damages estimates (as reported in sensitivity analysis) to the extent that existing plants lack controls (or have them but fail to operate them), though these average rates will typically decline in future as newer (usually cleaner) plants progressively replace older plants. ${ }^{21}$

Parry et al. (2014) used the same approach as above to estimate air pollution damages per GJ of natural gas from power plants, though these damages are far more moderate as gas produces minimal amounts of direct $\mathrm{PM}_{2.5}$ and $\mathrm{SO}_{2}$, and is also less $\mathrm{NO}_{\mathrm{x}}$ intensive than coal. $^{22}$ Air pollution damages for gas used in residences and industry were estimated in the same way as for motor fuels (see below) but, since the estimates are similar to those for gas power plants, the latter are used here for all natural gas usage.

Vehicle Externalities. Co-benefits from incorporating carbon charges in motor fuels include reduced air pollution, traffic congestion, accidents and (for the case of heavy trucks) road damage.

Air emissions from motor fuel combustion are released close to the ground and tend to remain locally concentrated rather than being dispersed over large distances. For these fuels, Parry et al. (2014) extrapolate national average intake fractions for emissions in

\footnotetext{
${ }^{19}$ Or more precisely, the 'value of a statistical life', that is, people's willingness to pay for reductions in mortality risk, expressed per life saved.

${ }^{20}$ There is less variation in local air emissions rates when expressed per unit of energy as opposed to per ton of coal.

${ }^{21}$ We gratefully acknowledge the help of Fabian Wagner who provided local air and carbon emissions factors for coal and other fuels which were calculated from the Greenhouse Gas and Air Pollution Interactions and Synergies (GAINS) model, developed by the International Institute for Applied Systems Analysis (IIASA).

${ }^{22}$ These estimates are for conventional gas (environmental costs might be somewhat higher for shale gas produced, for example, in the United States and Russia).
} 
different countries (based on average results from a large city-level database). Mortality effects and monetary damages are then inferred using the same procedures as above, and damages are expressed per liter of fuel use, based on country-level vehicle emission rates. For most countries, air pollution damages from gasoline are small relative to congestion and accident externalities, but are more substantial for diesel due to higher emission rates.

For the congestion component of corrective motor fuel taxes, what is needed is the value of extra travel (i.e., marginal) delay to other road users, averaged across urban and rural roads and peak and off-peak periods, due to an extra car kilometer driven. Parry et al. (2014) obtain rough estimates of this as follows.

First, average travel delay-the difference between time taken to drive a $\mathrm{km}$ at prevailing speeds and the time that would be taken at free-flow speeds-was estimated. Due to lack of better data, national average travel delays were extrapolated from a database containing 90 cities in different countries. Statistical regressions were used to relate travel delays to various transportation indicators at the city level, and then country level delays were predicted using the regression coefficients and country-level data for the same transportation indicators.

Second, marginal delay is inferred from average travel delay. It turns out that under a commonly-used specification for the relationship between travel speeds and traffic volume, marginal delay is a simple multiple of average delay-Parry et al. (2014) use a multiple of 4 (which, from the transportation engineering literature, seems a reasonable rule-of-thumb for congestion in urban centers).

Third, marginal delays are converted into passenger delays by scaling by car occupancy and are then expressed in monetary costs using the value of travel time which, based on reviews of empirical literature, is taken to be 60 percent of the market wage. Finally, marginal congestion costs are scaled back by a third, based on evidence suggesting that travel on congested roads (which is dominated by commuting) is less responsive to higher fuel prices than travel on uncongested roads. ${ }^{23}$

Parry et al. (2014) assess accident externalities by first breaking out country-level data on traffic fatalities into those assumed to reflect external risks, including pedestrian/cyclist fatalities and a fraction of fatalities in multi-vehicle collisions (as opposed to internal risks from single-vehicle collisions) and monetizing them using the same mortality values as used for pollution deaths. Other external costs (e.g., non-fatal injuries to pedestrians/cyclists, medical/property damages borne by third parties) are extrapolated from a limited number of country case studies.

\footnotetext{
${ }^{23}$ The congestion cost estimates are understated as they ignore some broader costs. For example, people may set off earlier or later to avoid the rush-hour peak, causing them to arrive earlier or later at their destination than they would otherwise prefer. Congestion also results in day-to-day uncertainty over travel times, making it more difficult to plan the day. Congestion costs can also be substantially higher when buses-which have high vehicle occupancies - account for a sizable share of vehicle kilometers.
} 
Lastly, Parry et al. (2014) measure the external costs of road damage by countries' spending on road maintenance, scaled back by 50 percent to crudely adjust for the role of weather in road deterioration.

Combined external costs from motor fuel use are summarized by the corrective (or Pigouvian) taxes. For gasoline, corrective taxes are based on externalities from cars, and for diesel, on a weighted average of externalities from (diesel) cars and trucks with weights equal to the respective fuel shares of these vehicles. ${ }^{24}$ In computing corrective taxes, externalities are scaled back to take into account the fact that only a fraction of the taxinduced reduction in fuel use comes from reductions in vehicle kilometers driven (the other fraction comes longer-run improvements in vehicle fuel economy which has no impacts on congestion, accidents, and road damage).

\footnotetext{
${ }^{24}$ Congestion costs per vehicle kilometer for trucks are taken to be twice those for cars.
} 


\section{References}

Bento, Antonio, Mark Jacobsen, and Antung A. Liu, 2012. "Environmental Policy in the Presence of an Informal Sector.” Discussion paper, Cornell University.

Bovenberg, A. Lans, and Lawrence H. Goulder, 1996. "Optimal 2001 Environmental Taxes in the Presence of Other Taxes." American Economic Review 84:1085-9.

Bovenberg, A. Lans, and Lawrence H. Goulder, 2001. "Neutralizing the Adverse Industry Impacts of CO2 Abatement Policies: What Does It Cost?" In Behavioral and Distributional Effects of Environmental Policy. C. Carraro and G. Metcalf ed. Chicago, University of Chicago Press, pp. 45-85.

Burnett, Richard T., C. Arden Pope, Majid Ezzati, Casey Olives, Stephen S. Lim, Sumi Mehta, Hwashin H. Shin, and others, 2013, "An Integrated Risk Function for Estimating the Global Burden of Disease Attributable to Ambient Fine Particulate Matter Exposure" (Unpublished; Ottawa, Ontario, Canada: Health Canada).

Clements, Benedict, David Coady, Stefania Fabrizio, Sanjeev Gupta, Trevor Alleyene, and Carlo Sdralevich (eds.), 2013. Energy Subsidy Reform: Lessons and Implications. International Monetary Fund, Washington, DC.

Dahl, Carol, 2012. "Measuring Global Gasoline and Diesel Price and Income Elasticities." Energy Policy 41: 2-13.

Feldstein, Martin. 1995. "The Effect of Marginal Tax Rates on Taxable Income: A Panel Study of the 1986 Tax Reform Act.” Journal of Political Economy 103: 551-72.

Feldstein, Martin, 1999. "Tax Avoidance and the Deadweight loss of the Income Tax." Review of Economics and Statistics LXXXI: 674-680.

Goulder, Lawrence H., Ian W.H. Parry, Roberton C. Williams, and Dallas Burtraw, 1999.

"The Cost-Effectiveness of Alternative Instruments for Environmental Protection in a Second-Best Setting." Journal of Public Economics 72: 329-360.

Gruber, Jonathan and Emmanuel S. Saez, 2002. "The Elasticity of Taxable Income: Evidence and Implications." Journal of Public Economics 84: 1-32.

IEA, 2014. World Energy Statistics and Balances. International Energy Agency, Paris, France.

IMF, 2014. Islamic Republic of Iran: Staff Report for the 2014 Article IV Consultation. Available at: http://www.imf.org/external/pubs/ft/scr/2014/cr1493.pdf. 
Krupnick, Alan J., Margaret Walls, Ian Pary, Tony Knowles and Kristin Hayes, 2010. Toward a New National Energy Policy: Assessing the Options. Resources for the Future and National Energy Policy Institute, Washington, DC.

Liu, Gang, 2004. "Estimating Energy Demand Elasticities for OECD Countries: A Dynamic Panel Data Approach.” Discussion Paper No. 373, Statistics Norway.

Nemet, Gregory F., Tracey Holloway and Paul Meier, 2010. "Implications of Incorporating Air-Quality Co-Benefits into Climate Change Policymaking." Environmental Research Letters 5: 1-9.

NRC, 2009. The Hidden Costs of Energy. National Research Council, Washington, DC.

OECD, 2010. Taxation, Innovation and the Environment. Organization for Economic Cooperation and Development, Paris, France.

Parry, Ian W.H., 1995. "Pollution Taxes and Revenue Recycling." Journal of Environmental Economics and Management 29: S64-S77.

Parry, Ian W.H. and Antonio M. Bento, 2000. “Tax Deductions, Environmental Policy, and the "Double Dividend" Hypothesis." Journal of Environmental Economics and Management 39: 67-96.

Parry, Ian W.H. and Roberton Williams, 2010. "What are the Costs of Meeting Distributional Objectives for Climate Policy?" B.E. Journal of Economic Analysis \& Policy 10, Issue 2 (Symposium), Article 9.

Parry, Ian W.H., Dirk Heine, Shanjun Li, and Eliza Lis, 2014. Getting Energy Prices Right: From Principle to Practice. International Monetary Fund, Washington, DC.

Parry, Ian W.H., Roberton C. Williams and Lawrence H. Goulder, 1999. "When Can Carbon Abatement Policies Increase Welfare? The Fundamental Role of Distorted Factor Markets." Journal of Environmental Economics and Management 37: 52-84.

Saez, Emmanuel, Joel Slemrod, and Seth H. Giertz, 2012. "The Elasticity of Taxable Income with Respect to Marginal Tax Rates: A Critical Review." Journal of Economic Literature 50: $3-50$.

Salehi-Isfahani, Djavad, 2011. "Iran: Subsidy Reform amid Regional Turmoil.” Available at: www.brookings.edu/research/opinions/2011/03/03-iran-salehi-isfahani.

Sterner, Thomas, 2007. "Fuel Taxes: An Important Instrument for Climate Policy." Energy Policy 35: 3194-3202. 
Trüby Johannes and Paulus Moritz, 2011. "Market Structure Scenarios in International Steam Coal Trade." Working paper 11/02, Institute for Energy Economics at the University of Cologne.

US IAWG, 2013. Technical Support Document: Technical Update of the Social Cost of Carbon for Regulatory Impact Analysis Under Executive Order 12866. Interagency Working Group on Social Cost of Carbon, United States Government, Washington, DC.

West, J. Jason, et al., 2013. "Co-Benefits of Mitigating Global Greenhouse gas Emissions for Future Air Quality and Human Health." Nature Climate Change 3: 885-889.

WHO, 2014. Public Health, Environmental and Social Determinants of Health. World Health Organization, available at: www.who.int/phe/health_topics/outdoorair/databases/en/.

Woodcock, James, et al. 2009. "Public Health Benefits of Strategies to Reduce GreenhouseGas Emissions: Urban Land Transport." Health and Climate Change 2, 374: 1930-1943.

Zhou Ying, Jonathan I. Levy, John S. Evans, and James K. Hammitt, 2006 "The Influence of Geographic Location on Population Exposure to Emissions from Power Plants throughout China.” Environment International 32: 365 - 373. 